\title{
Balanced Scorecard Application and its Challenges
}

Ahmed Deghash*

Al-Aqsa Media Network Institution,

Gaza Strip, Palestine

Email: haniedu@hotmail.com

Received December, 2017; Accepted January, 2018

Abstract: Institutions seek to obtain a comprehensive picture of their financial and managerial performance by providing indicators and measures for evaluating internal and external performance in the short and long term based on their strategic needs. Institutions' performance is measured through managerial measurement tools to improve the decision-making process and achieves the institutions' strategic objectives. Among tools used in measuring performance, there are traditional tools that rely on financial measures and other tools that rely on financial and non-financial performance measures, such as the balanced scorecard. This study focuses on the balanced scorecard as a tool used to measure performance, the reasons that led to its emergence, its dimensions, the axes contained in each dimension, its basic characteristics, advantages, the success drivers, the challenges facing its application, and the application steps.

Keywords: Balanced Scorecard; Financial and non- Financial Performance

Type: Research paper

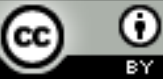

This work is licensed under a Creative Commons Attribution 4.0 International License.

\section{DOI: 10.51325/ijbeg.v2i1.41}

تطبيق بطاقة الأداء المتوازن والتحديات التي تواجه تنفيذه

الملخص:

تسعى المؤسسات الى الحصول على صورة متكاملة عن أدائها المالي والإداري من خلال توفير مؤشرات

ومقاييس لتقييم الأداء الداخلي والخارجي على المدى القصير والطويل وفقاً لاحتياجاتها الاستراتيجية، ويتم قياس الأداء من خلال أدوات قياس إدارية بهدف تحسين اتخاذ القرار وتحقيق أهداف المنشأة الاستراتيجية، ومن ضمن الأدوات المستخدمة في قياس الأداء هناك أدوات تقليدية تعتمد على مقاييس الأداء المالية وأخرى حديثة تعتمد على مقاييس الأداء المالية والغير المالية ومن ضمنها بطاقة قياس الأداء المتوازن. هذه الدراسة تتناول مفهوم بطاقة الأداء المتوازن والأسباب التي أدت إلى ظهورها والأبعاد المكونة لها والمحاور التي يحتويها كل بُعد والصفات الأساسية لها والمزايا ومقومات نجاح تطبيق بطاقة الأداء المتوازن والتحديات التي تواجه تطبيقها، وخطوات تطبيق بطاقة قياس الأداء المتوازن.

الكلمات المفتاحية: بطاقة الأداء المتوازن، الأداء المالي والغير مالي

مقدمة الدراسة

في ظل التطور والتغيير السريع المستمر الذي يطرأ على بيئة الأعمال أصبحت الطريقة التقليدية للتزويد

بتلك المعلومات لا تفي بالغرض إذ تعاني من مشكلة الوقت الضائع بين علميات التخطيط والحاجة إلى التزويد 
بالمعلومات، وكذلك من مشكلة عدم وجود لغة مشتركة للتفاهم بين المديرين والمسئولين عن أنظمة المعلومات، وهنا ظهرت الحاجة إلى نوع جديد من التفكير الاستراتيجي يتبنى مداخل حديثة للتطوير وقياس الأداء وتوفير المعلومات

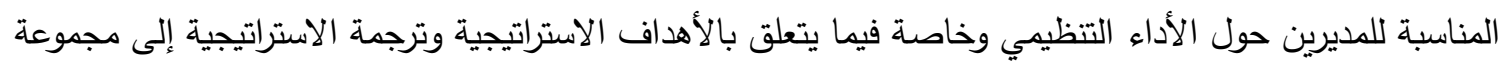

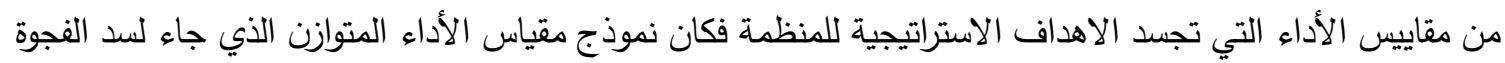
بين أنظمة القياس التقليدية واستراتيجية المنشأة البعيدة المدى من خلال ربط هذه الاستراتيجية بأعمال ونثاطات المنشأة قصيرة الأجل، حيث يتم على أساس ذلك كما بينه (Simons) الربط بين جانبين أساسيين للاستراتيجية، الأول تحديد الأفعال والأنشطة المطلوبة التي تقع في المستوى الأدنى من مستوى تحديد مقاييس الأداء، وبذلك تعتبر هذه المقاييس رابطاً بين الأهداف والخطط وبين الأنشطة المنجزة واللازمة لتحقيق هذه الأهداف والخطط (زويلف ونور ، . 32 :2005

Kaplan \& وتعد بطاقة قياس الأداء المتوازن إحدى الوسائل الإدارية المعاصرة التي قدمها كل من

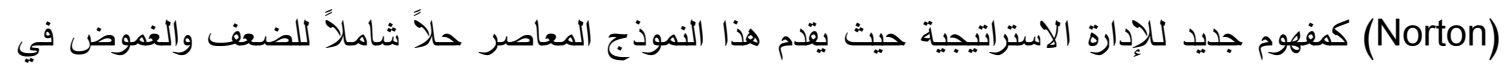
التوجه القديم للنظام الإداري الذي يركز على الأداء المالي فقط من خلال إضافة أبعاد أخرى تحول الخطة الاستراتيجية

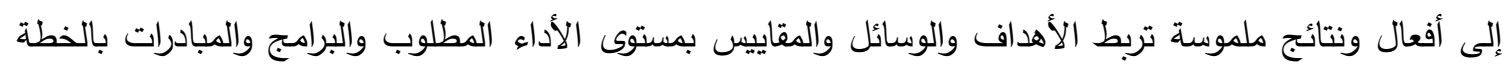
الاستراتيجية (نديم، 2013: 14).

مفهوم بطاقة الأداء المتوازن عرف (Kaplan and Norton:1992:7) بطاقة قياس الأداء المتوازن على أنه نظام شامل لقياس الأداء من منظور استراتيجي، يتم بموجبه ترجمة استراتيجية تتظم الأعمال إلى أهداف استراتيجية (Strategic Objectives) ومقاييس (Measures) وقيم مستهدفة (Targets) وخطوات إجرائية تمهيدية واضحة (Initiatives). وعُرفت بأنها إطار متكامل لقياس الأداء الاستراتيجي، تتكون من مجموعة من المقاييس المالية وغير المالية والتي تتلاعم مع أهداف واستراتيجية المنظمة وكذلك مع أهداف واستراتيجيات الوحدات الفرعية في المنظمة (الأقسام)، وترتبط هذه المقاييس بين بعضها البعض بعلاقة السبب والنتيجة، وهذه العلاقة هي التي تعمل على تحسين النتائج

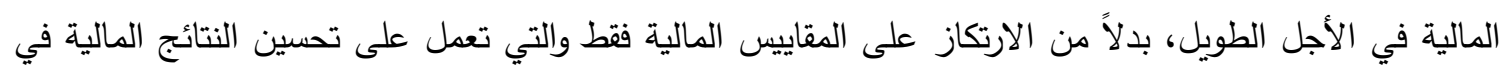
الأجل القصير ( Alareeni and Aljuaidi, 2014; Alareeni and Branson, 2013; Alareeni and Deghish, 2016; Alareeni, 2018, 2019, وأيضاً تُعرف بأنها أداة تستخدم لنقل وتوصيل استراتيجية المنظمة إلى الوحدات والمستويات الإدارية المختلفة،

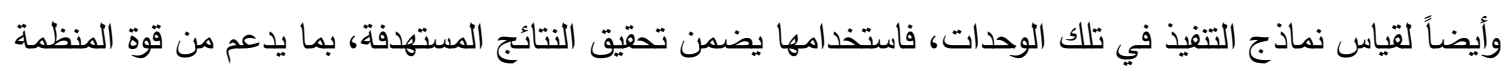

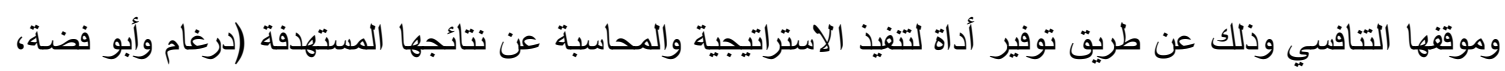
. $750: 2009$

وعرفها (المغربي وغربية، 2006، 192) بأنها نظام إداري يهدف إلى مساعدة الملاك والمديرين على ترجمة رؤية واستراتيجيات شركاتهم إلى مجموعة من الأهداف والقياسات الاستراتيجية المترابطة. ويلخص (2002:3،Morisawa) ) جوهر بطاقة الأداء المتوازن طبقاً للخبرة التي استمدتها مؤسسة من من تقديم إطار لبطاقة الأداء المتوازن تم استخدامه في أكثر من عشرين شركة يابانية في النقاط الخمس التالية: 1- تحقيق التوازن بين الأهداف الإدارية قصيرة ومتوسطة وطويلة الأجل داخل مختلف مقاييس الأداء. 2- تقوية تفهم أهمية تكوين مؤشرات وصفية غير مالية بجانب المؤشرات المالية. 
3- إزالة الغوض عن طريق الاحتفاظ بالمؤشرات الكمية.

4- نشر التعلم التنظيمي من خلال دورة متكررة لمراجعة النظرية.

5- توفير خطة اتصال استراتيجية تربط الإدارة العليا للمنظمة بالأفراد العاملين فيها.

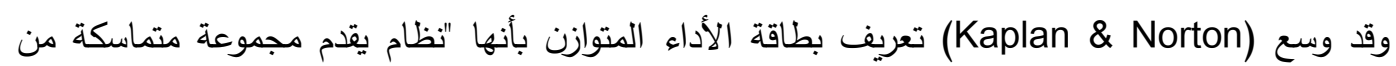

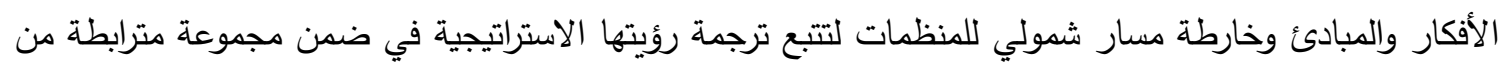
مقاييس الأداء التي لا تستخدم في مجال الأعمال فقط، ولكن لتحقيق الترابطواتصال الاستراتيجية بالأعمال، ولمساعدة

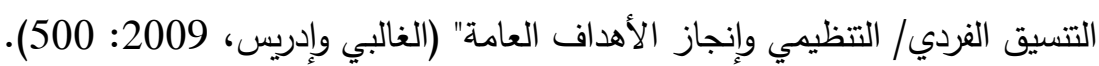

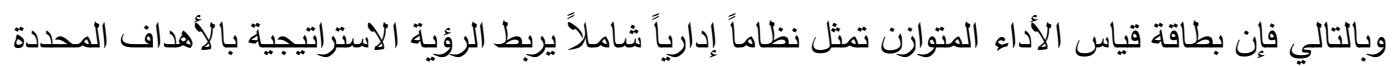
ويترجم الأهداف إلى مقاييس متوازنة من خلال الاعتماد على مقاييس مالية وغير مالية، ويتم توزيعها على أبعاد

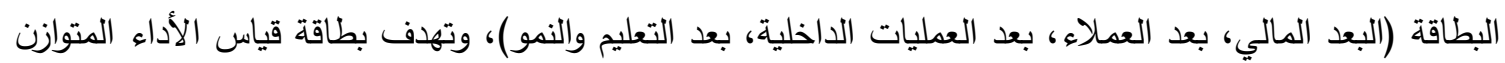

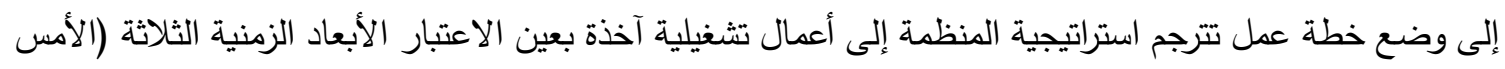

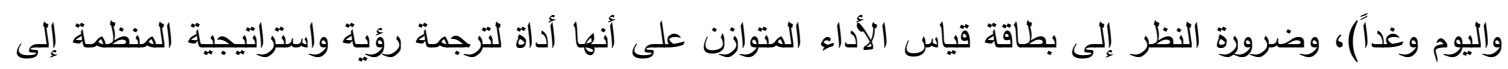

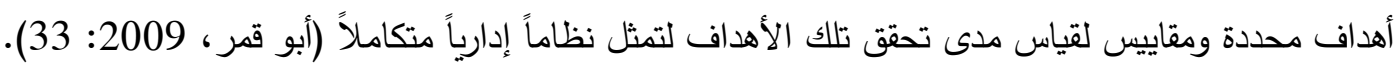
ويرى الباحث أن بطاقة قياس الأداء المتوازن هي نظام إداري متكامل لقياس الأداء ويعتبر أداة من أدوات الإدارة الاستراتيجية الذي يحقق التخطيط الاستراتيجي ويدعم المركز التتافسي للمنظمة لتقييم أنشطتها وفق رؤيتها واستراتيجياتها ويستند الى مؤشرات مالية (بعد مالي) ومؤشرات غير مالية (بعد العملاء - بعد العمليات الداخلية بعد النمو والتعلم - البعد الاجتماعي). أسباب ظهور بطاقة الأداء المتوازن ظهرت بطاقة قياس الأداء المتوازن Balanced Scorecard (BSC) لمواجهة القصور في أنظمة الرقابة المالية التقليدية، فلقد رأى البعض أن الرقابة المالية التقليدية توقفت عن التطور منذ عام 1925م، فهم يرون أن جميع الإجراءات الإدارية والمحاسبية التي نعرفها اليوم موجودة بالفعل منذ زمن بعيد مثل (الميزانيات، التكاليف المعيارية، تسعير المخزون، نموذج دوبونت ... الخ)، ولم تعد تكفي لتحقيق طموحات المنظمات في ظل التحديات المعاصرة (المغربي وغربية، 2006: 189).

حيث تعرضت بيئة الأعمال داخل وخارج المنظمات إلى مجموعة من المتغيرات أثرت على مختلف نواحي الأداء بها مما دعا المنظمات إلى الاتجاه نحو تطبيق بطاقة قياس الأداء المتوازن (Kaplan and Norton)،

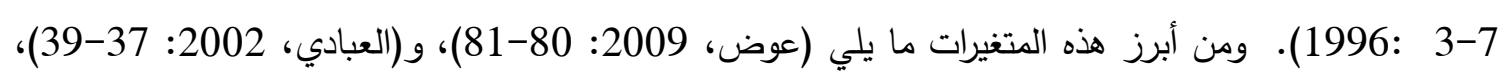
و (أبو قرر، 2009: 35-36): 1. زيادة حدة المنافسة على المستوين المحلي والدولي على أثر ظهور التكتلات الاقتصادية الدولية، واندماج منشآت الأعمال في كيانات كبيرة، والتطبيق الفعلي لاتفاقية تحرير التجارة (الجات)، وإزالة الحواجز والقيود الجمركية.

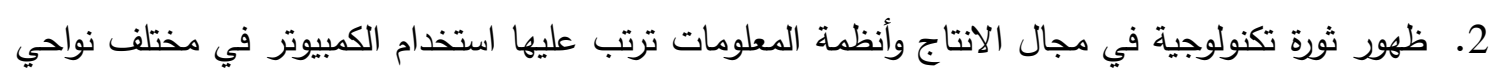
الأنشطة بالمنظمة ابتداءً من مرحلة التصميم للمنتج ومروراً بمرحلة التخطيط للاحتياجات، ثم مرحلة التتفيذ

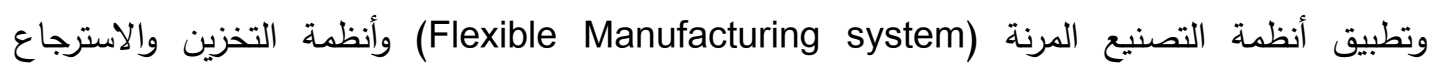
الأوتوماتيكي، ثم مرحلة الرقابة بالإضافة إلى استخدام أساليب قواعد البيانات في تثغيل البيانات الداخلية والخارجية وإمداد الإدارة بالمعلومات اللازمة لاتخاذ القرارات بسرعة ودقابة بالإنة فائقة. 
3. ظهور تغيرات وتحولات جذرية في أهداف منظمات الأعمال للمحافظة على بقائها وسط ظروف المنافسة الثديدة،

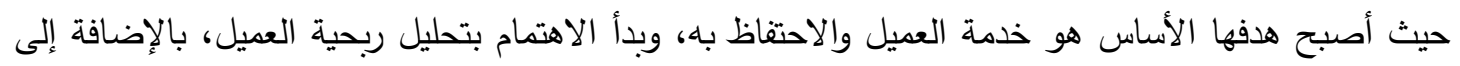
الاهتمام المستمر بالتحسين المستمر (Continuous Improvements) في الجودة. 4. حدوث تغيرات جذرية في نظام وفلسفة الإدارة ومداخل اتخاذ القرارات وأساليب الإنتاج ترتب عليها تطبيق الإدارة الاستراتيجية، وظهور فلسفة التوقيت المنضبط في المخزون والإنتاج (Just In Time)، ونظام الإنتاج المرن (Flexible Manufacturing System) التركيز على مرحلة الإنتاج إلى التركيز على كل مرحلة من مراحل دورة حياة المنتج، وتحول الاهتمام برقابة الجودة إلى انتهاج سياسة التحسين المستمر ، واستخدام أسلوب هندسة القمة وقد نتج عن ذلك كله مله مزايا تتافسية.

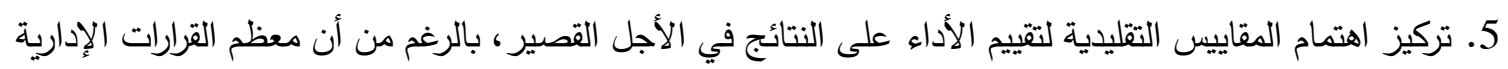

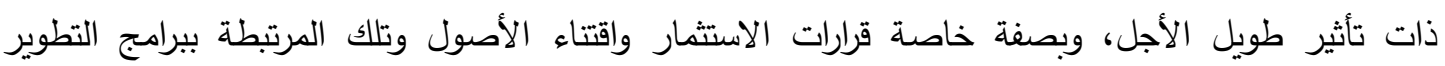

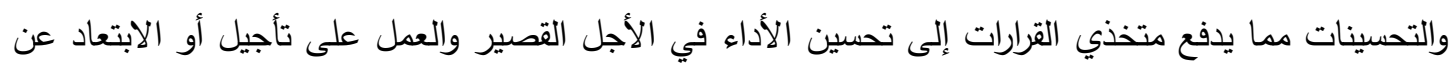

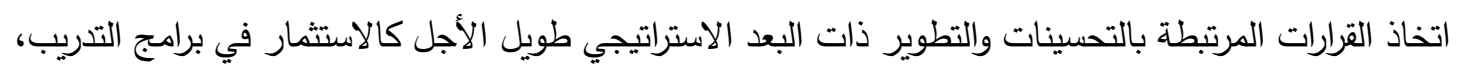

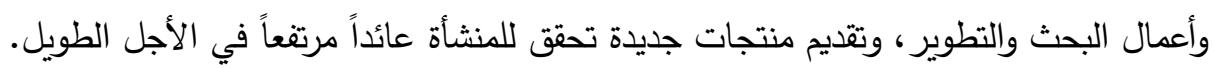
أبعاد بطاقة قياس الأداء المتوازن لقد أكد كل من (1992:Kaplan and Norton (19) ) أن بطاقة قياس الأداء المتوازن تتكون من أربعة أبعاد رئيسة وهي كالتالي (أبو قمر، 2009: 31:

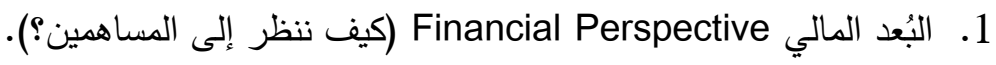
2. بُعد العملاء Customer Perspective (كيف ينظر إلينا العملاء؟). 3. بُعد العمليات الداخلية Internal Business Processes (ما الذي يجب أنعاء أن نتفوق به؟). 4. بُعد التعلم والنمو Learning and Growth Perspective (هل يمكن أن نستمر في التحسين وخلق القيم؟). حيث يسترشد الباحث بالبعد الخامس وهو البعد الاجتماعي لبطاقة الأداء المتوازن. 5. البعد الاجتماعي Social Perspective (كيف نخدم ونساهم في تطوير المجتمع؟). 
شكل رقم (1-3) أبعاد بطاقة قياس الأداء المتوازن

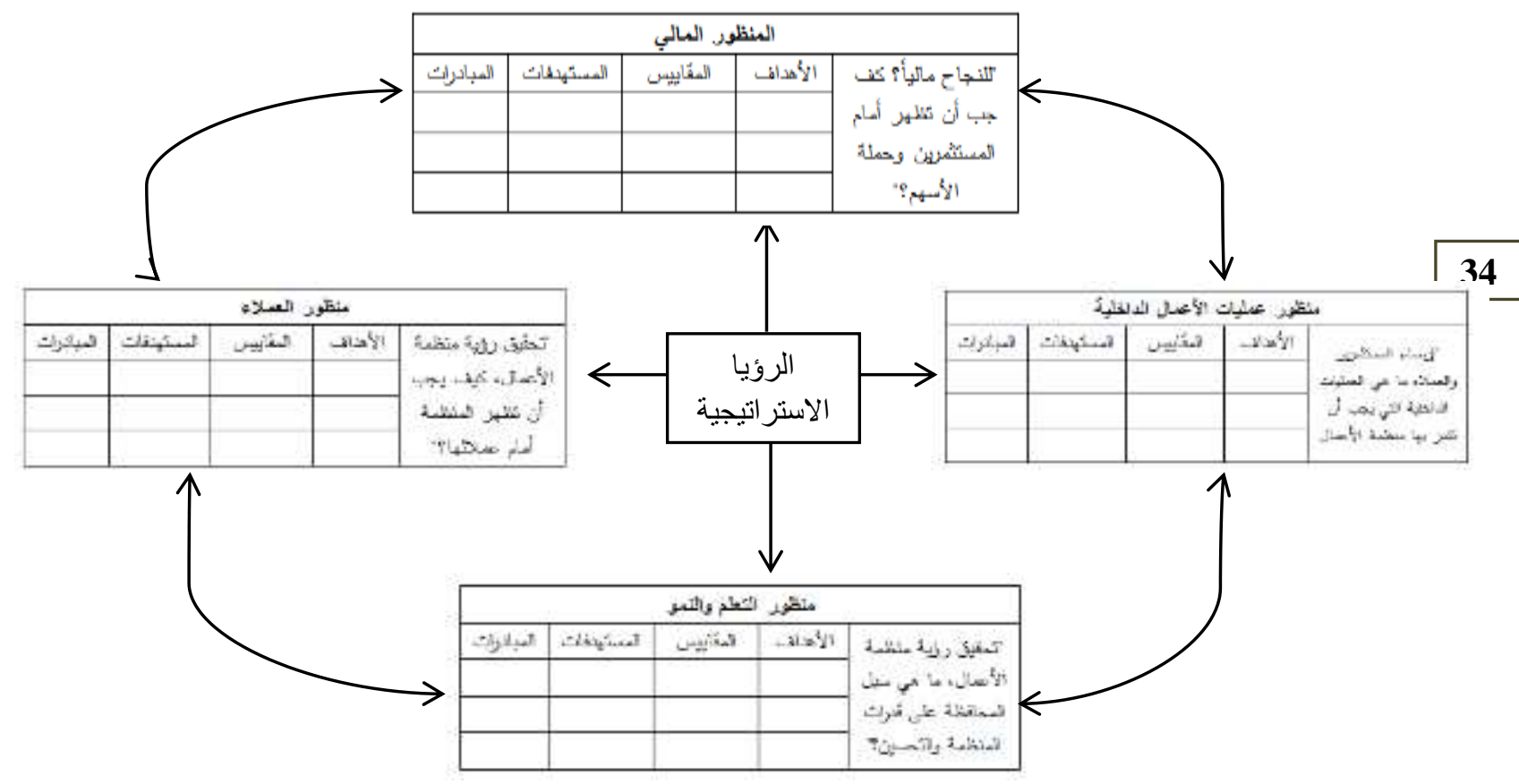

(الغالبي وإدريس، 2009: 1996: 76،Kaplan \&Norton)،

والثكل رقم (1-3) يبين أن الأهداف الاستراتيجية يجب أن تقسم إلى أهداف مخططة متعاقبة وتتحقق على وهلى

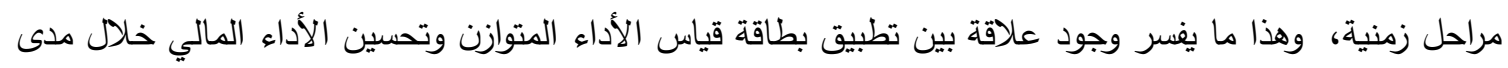
زمني طويل، وكذلك وجود علاقات سببية بين مقاييس الأداء تتلخص في التحسن في التعلم والنمو يؤدي إلى تحسن

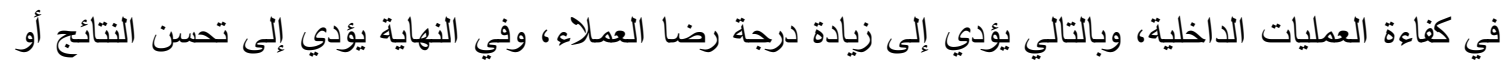
الأداء المالي، ومن ثم زيادة الدعم للمجتمع. وتهتم بطاقة قياس الأداء المتوازن بثلاثة قطاعات من الأطراف ذات المات المصلحة بالمنظمة وهم المساهمون والعملاء والعاملين، ويجب أن تتلاءم المقاييس التي يتم اختيارها في كل جانب من هذه الجوانب مع استراتيجية

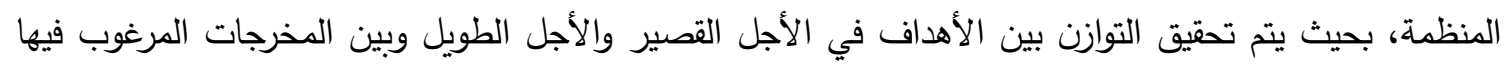

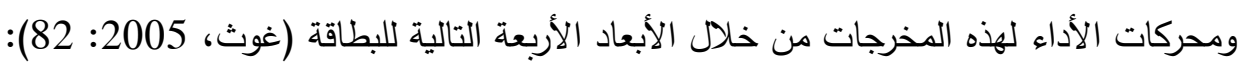
1- البُعد المالي Financial Perspective: (كيف سنحقق النجاح المالي وفقاً لما يرغبه المساهمون؟) على الرغم من الدور المهم للأهداف غير الملموسة وتأثيرها على الأجل الطويل، فإن العديد من الكتاب

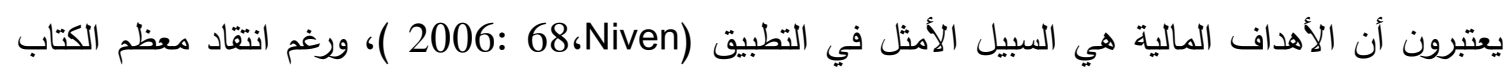
والباحثين للمقاييس المالية ودعمهم للمقاييس غير المالية فإنهم لا ينكرون دور المقاييس المانيس المالية في تقييم الأداء، ولا يمكن تجاهل المقاييس المالية بل يجب أن تستخدم مع المقاييس غير المالية جنباً إلى جنب.

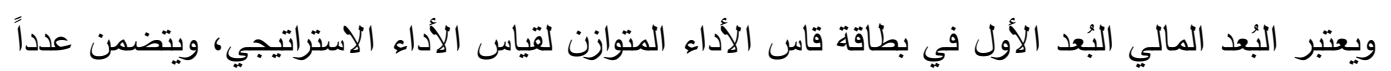

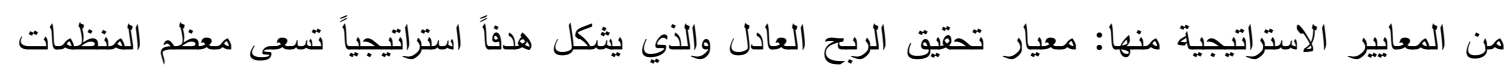

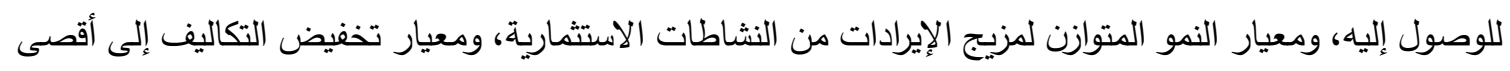
حد ممكن وذلك لتحقيق أقصى فاعلية ممكنة، ومعيار تعظيم الثروة للمساهمين والمودعين من خلال تحقيق عوائد الإيرات 
حقيقية على الاستثمار، ومعيار تحقيق قيمة اقتصادية مضافة Economic Value Added (EVA)، (درغام وأبو فضة، 2009: 748).

ويتم تقييم الأداء المالي من خلال استخدام النسب المالية والتحليل المالي المستتد إلى القوائم المالية، ويستتج منها الربح المتحقق وحجم المبيعات، ويجيب هذا البُعد عن التساؤل في إيجاد آلية تعمل على خلق قيمة لمالكي

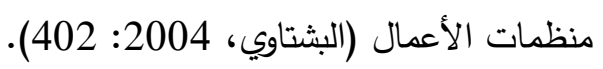

وليس من الضروري أن تؤخذ المقاييس المالية دائماً من النظام المحاسبي للشركة، فقد تكون القيمة أو السعر التراس

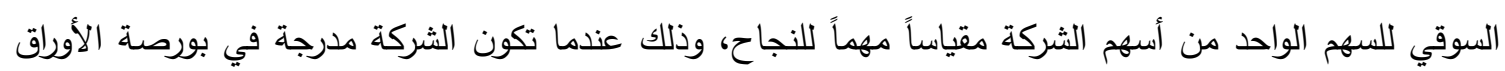
المالية (المغري وغربية، 2006: 256).

إن مقاييس الأداء المالية تبين مدى الالتزام بتتفيذ الخطط الاستراتيجية، حيث تم التعبير عن الخطط

الاستراتيجية بأهداف ومقاييس أداء، والتي تبين مدى التحسن في النتائج النهائية للمنظمة (2006: 16،Niven ).

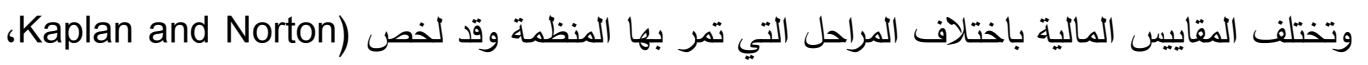
48 :1996) هذه المراحل في ثلاثة مراحل رئيسة هي مرحلة النمو (Growth)، ومرحلة الاستقرار (Sustain)،

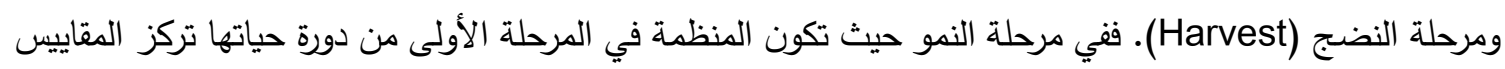
المالية على زيادة المبيعات والدخول في أسواق جديدة واجتذاب عملاء جدد والمحافظة على مستوى مناسب للإنفاق

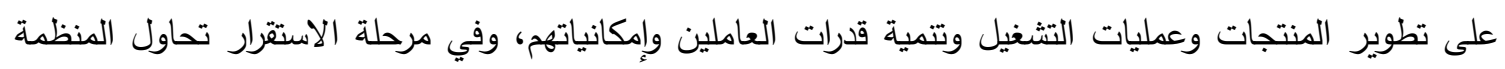
إعادة استثمار أموالها واجتذاب المزيد من الاستثمارات، وتركز المقاييس المالية في هذه المرحلة على المقاييس التقليدية

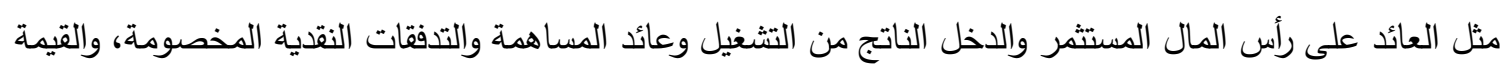
الاقتصادية المضافة، أما مرحلة النضج فإن المنظمة ترغب في حصاد نتائج الاستثمارات في المرحلتين السابقتين،

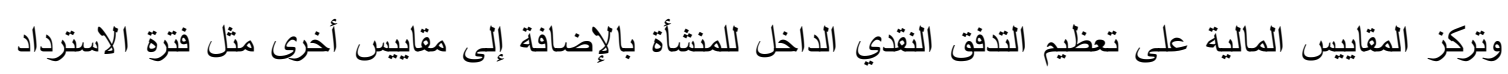
وحجم الإيرادات (الثيشيني، 2004: 121).

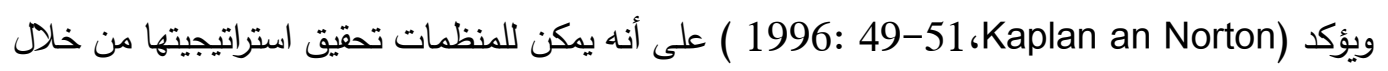
ثلاثة أساليب رئيسة هي (أبو قمر، 2009: 39).

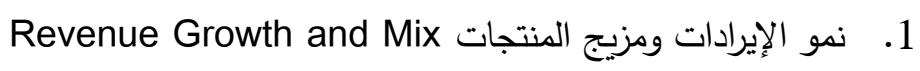
ويقصد بنمو الإيرادات ومزيج المنتجات التوسع في المنتجات والخدمات، ومحاولة اجتذاب عملاء جدد،

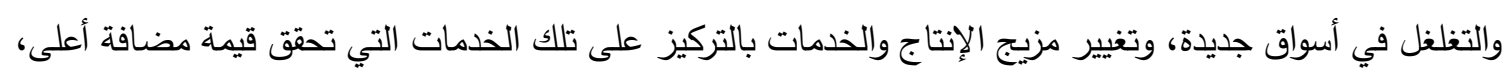
وإعادة تسعير المنتجات والخدمات.

2. تخفيض التكاليف وتحسين الإنتاجية Cost Reduction and Productivity ويقصد بتخفيض التكاليف وتحسين الإنتاجية محاولة تخفيض التكاليف المباشرة للمنتجات والخدمات وتخفيض الإنساتية التكاليف غير المباشرة، وتوزيع الموارد العامة أو المشتركة على وحدات أو قطاعات المنظمة المختلفة.

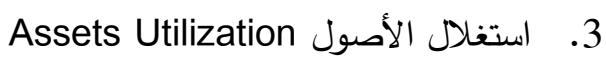

ويقصد باستغلال الأصول تخفيض مستويات رأس المال المطلوب لتحقيق حجم ومزيج معين من الأعمال.

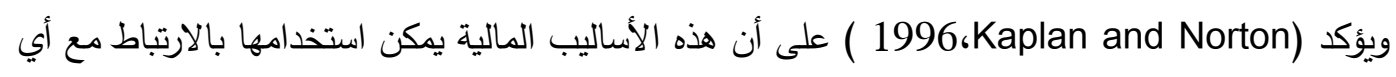
استراتيجية عامة سواء في مراحل النمو أو الاستقرار أو النضج، ولكن قد تختلف المقاييس باختلاف استراتيجية كل وحدة نشاط (عوض، 2009: 101)، ويوضح الجدول رقم (1-3) كيفية استخدام بطاقة قياس الأداء المتوازن في تحديد الاستراتيجية المالية لوحدة النشاط وكيفية تعديل الأهداف والمقاييس المالية لتتناسب مع هذه الاستراتيجية. 


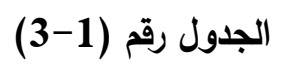

تطويع المقاييس لتتناسب مع استراتيجية وحدة النشاط وأساليب تحقيقها

\begin{tabular}{|c|c|c|c|c|}
\hline \multicolumn{3}{|c|}{ الأساليب المالية لتحقيق الاستراتيجية } & \multirow[b]{2}{*}{ 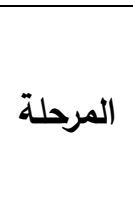 } & \\
\hline استغلال الأصول & ت تحسين الإنتاجية & نمو الإيرادات ومزيج & & \\
\hline - - نسبة رأس المال المستثر - نسبة تكلفة البحوث الخدمات & & 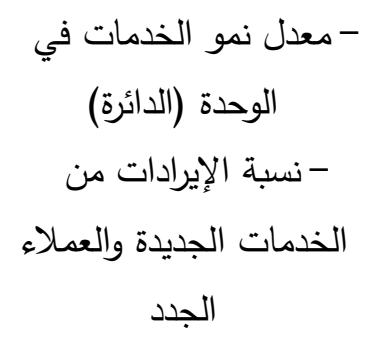 & النمو & استراتيجية \\
\hline - معدلات رأس المال العامل - معدلات العائد على رأس المال المستثمر (بالنسبة الأصول الرئيسية) & - - التكلفة بالمقارنة بالدنافسين - & 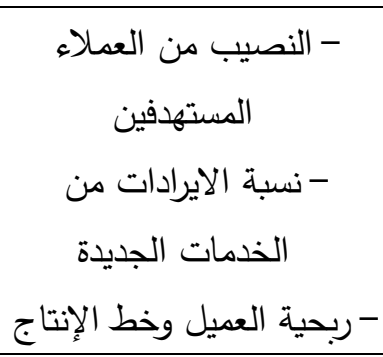 & الاستقرار & النشاط \\
\hline - فورة - دالاسترداد & - تكلفة الخدمة (لكل وحدة & - - ربحية العميل وخط الإنتاج & النضج & \\
\hline
\end{tabular}

المصدر : (1996: 52،Kaplan and Norton)

2- بُعد العملاء Customer Perspective (عند تحقيق رؤيتا، كيف سنبدو في نظر عملائنا؟).

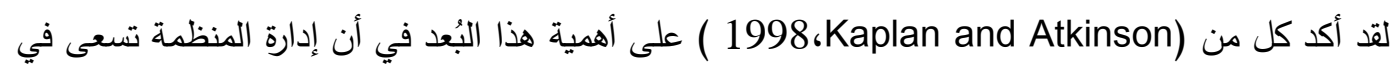
الوصول إلى تحقيق أعلى درجة لإرضاء العملاء، إذ أن درجة الرضا تؤثر في نسبة الحصول على عملاء جداء

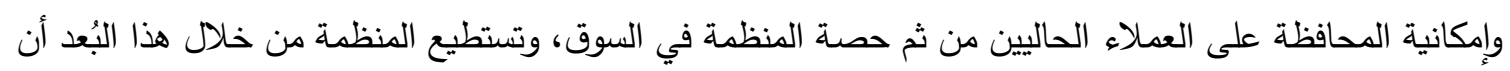
تحصل على الإجابة عن الكيفية التي ينظر بها العملاء إليها (البشتاوي، 2004: 402).

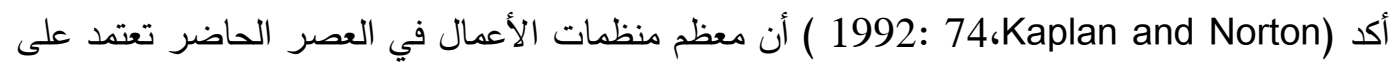
وضع متطلبات وحاجات العملاء في قلب استراتيجيتها، لما يعكسه هذا المحور من أهمية كبيرة تتعكس على نجاح

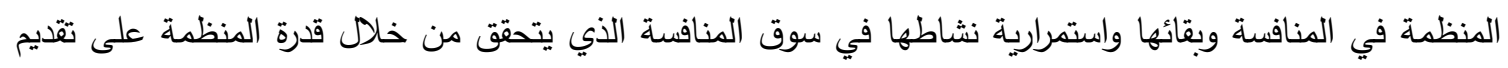

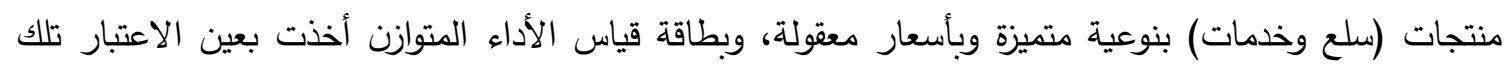

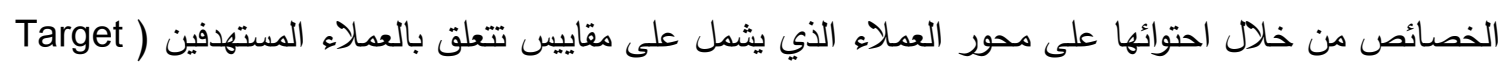

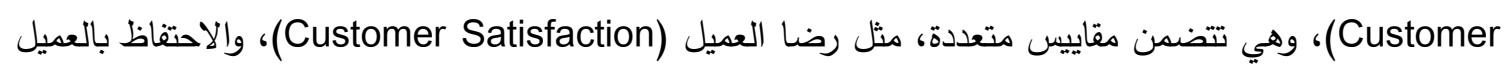

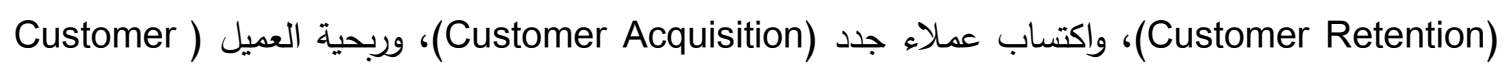
Profitability)، والنصيب في السوق (Market share)، في القطاعات المستهدفة، والقيمة من وجهة نظر العميل، وابل، 
التي تعتمد بثكل أساس على إتباع المنظمة لأسلوب تحليل ربحية العملاء (Customer Profitability) (أبو جزر، .53-52:2012

ويهتم هذا البُعد بالأساليب التي تخلق القيمة للزبائن، وما هي القيمة التي ترضى الزبون ولماذا سيكون راغب

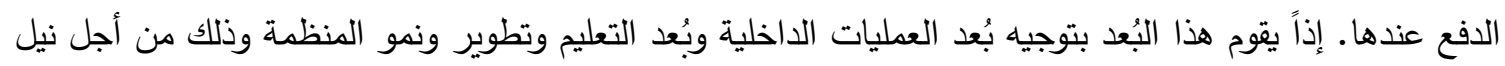

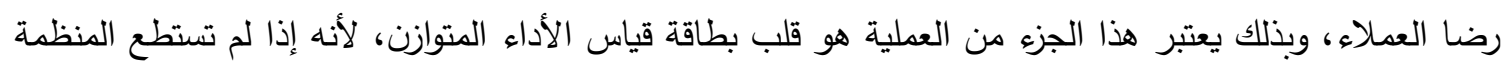

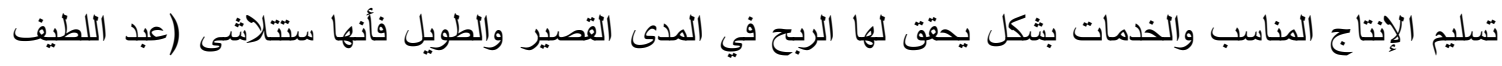

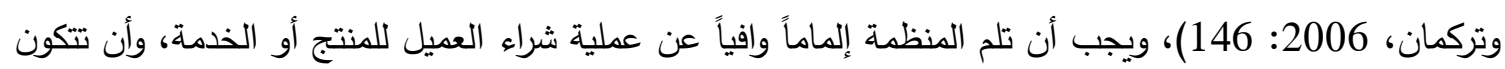

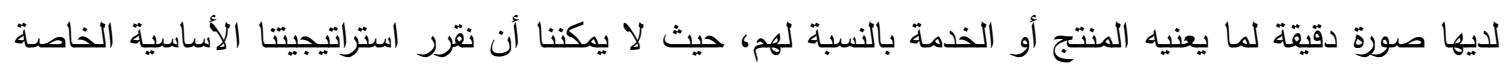
بالعملاء والأسواق إلا بعد تحليل كافة البيانات الخاصة بالعملاء والأسواق.

إن مقاييس أداء بُعد العملاء تعتمد على التغير الذي حصل في بيئة العصر الحالي إذ جعل المنافسة مفتوحة وحادة، ولذلك فإن هدف البقاء والاحتفاظ بحصة واسعة من السوق يعد من أحد أهم عناصر الاستمرار للمنظمات التي لتئي يجب أن تثبت قدرتها على تقديم منتجات أو خدمات بنوعيات عالية الجودة وبتكلفة منخفضة وبسعر معقول (البشتاوي، البتاء . 2004

ويعد مقياس ربحية العميل من المقاييس المهمة نسبياً فقد يظهر هذا المقياس أن بعض العملاء المستهدفين

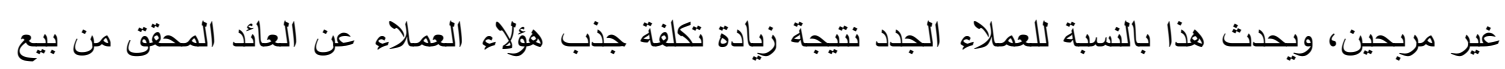

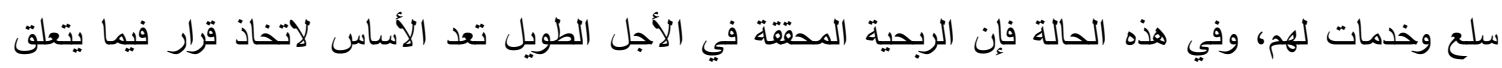

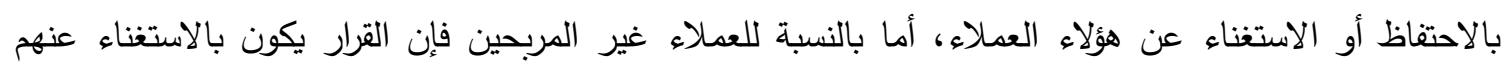

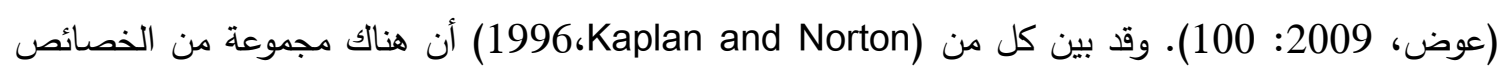

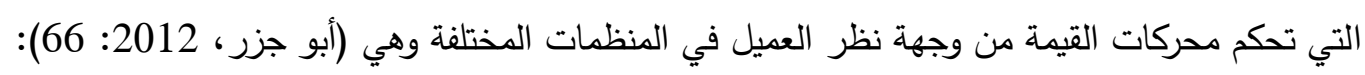

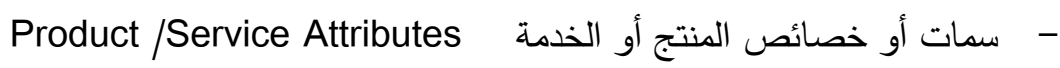
Customer Relationship

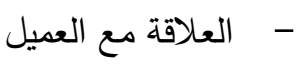
Image and Reputation

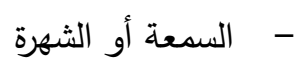

وقد أكد (1996:67،Kaplan and Norton) ) على انه من الممكن ان يتضمن جانب سمات وخصائص الجمات

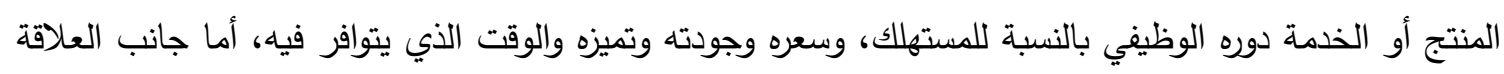

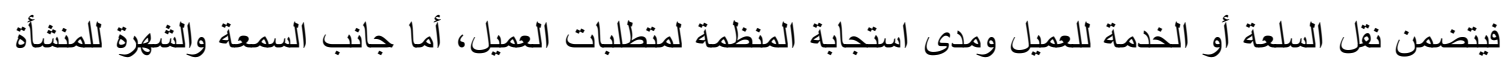

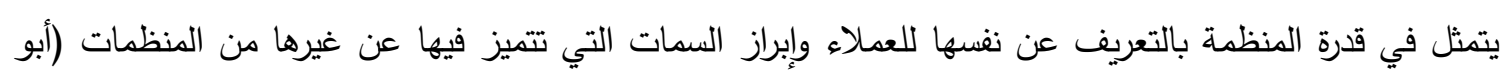
قمر ، 2009: 42). ويوضح الثكل رقم (2-3) مقياس القيمة من وجهة نظر العميل وكيفية ربطه بمقاييس المخرجات. 
الثكل رقم (2-3) مقياس القيمة من وجهة نظر العميل وكيفية ربطه بمقاييس المخرجات

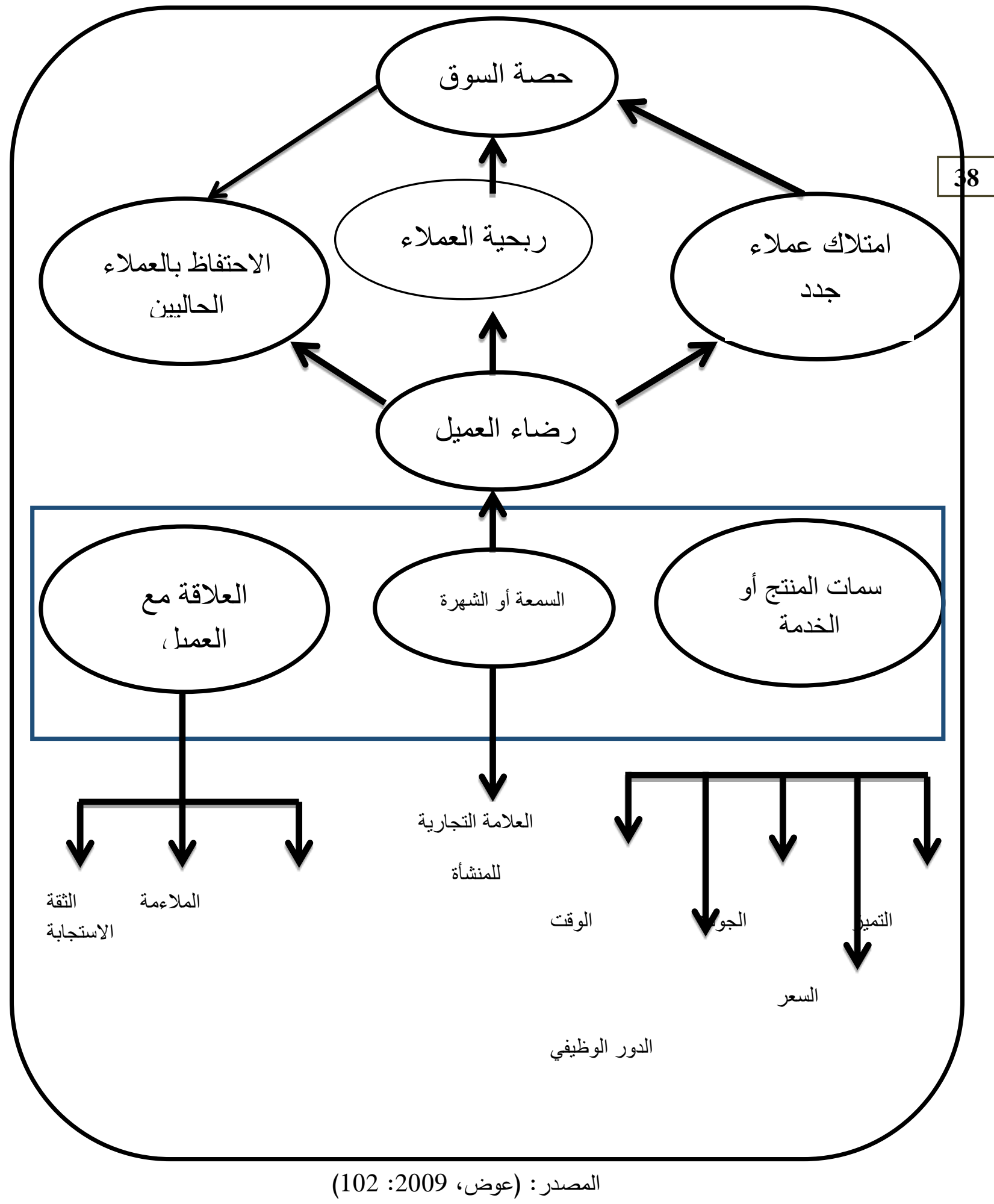

3- بُعد العمليات الداخلية Internal Business Processes Perspective (لإرضاء المساهمين

والعملاء، ما هي العمليات التشغيلية التي جب أن نتفوق فيها؟).

ركز هذا البُعد على العوامل والإجراءات التشغيلية الداخلية المهمة التي تُمكن المنظمة من التميز وبالتالي

تؤدي إلى تحقيق رغبات العملاء المتوقعة منها بكفاءة وفاعلية، وأيضاً إلى تحقق نتائج مالية متميزة مرضية للمساهمين، لئهن 
ويدخل أيضاً في هذا الجانب الاختراعات والابتكارات والتي تؤدي إلى إدخال منتجات وخدمات جديدة تحقق رضا العملاء الحاليين والجدد (عوض، 2009 203ن 103).

ويهدف بُعد العمليات الداخلية إلى تحديد العمليات المهمة التي يجب أن تتفوق فيها المنظمة لتتفيذ الاستراتيجية، أي أنه يجب أن تركز المنظمة على العمليات الداخلية التي تؤثر على رضا العملاء وبالتالي على تحقيق الأهداف

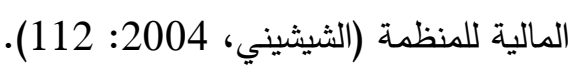

حيث إن الأداء الجيد لخدمات العملاء ينشأ من العمليات والقرارات والتصرفات التي تحدث داخل المنظمة، ومن ثم يطلب من المديرين التركز على العمليات الداخلية الأساسية وتحقيق التتاسق بينها لخلق قيمة للعملاء

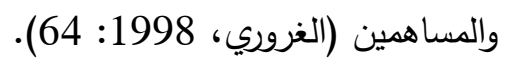

كما أن هذا البُعد يهتم بقياس الأداء المستقبلي للمنظمة من خلال عرض الأنشطة والعمليات الداخلية التي

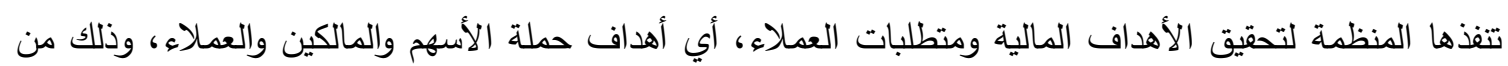
خلال استحداث وابتكار منتجات جديدة وتطويرها في ضوه محددات السوق، وتثخيص طبيعة السوق واحتياجات

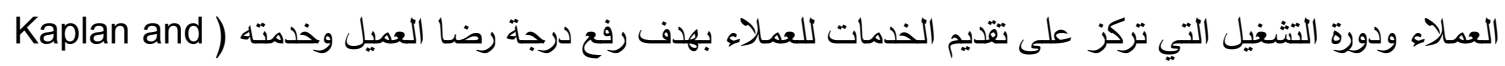

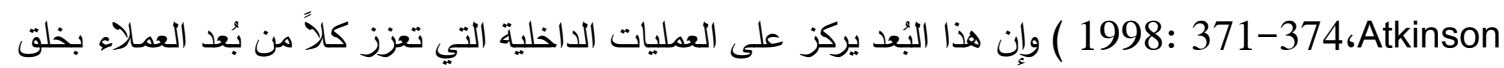
قيمة لهم، والبُعد المالي بزيادة ثروة المساهمين، وكذلك يركز على تحديد الحلقات التي سوف تحسن الأهداف والمساعدة

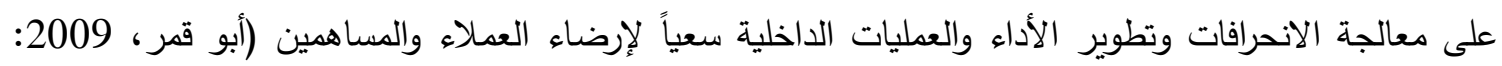

وتتقسم سلسلة الأنشطة والمراحل الداخلة لمنظمات الأعمال التي تحدث القيمة المجزة للعميل أو المستهلك

$$
\text { إلى ثلاث دورات كما هي موضحة بالثكل رقم (3-3): }
$$

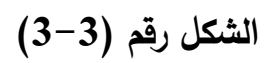

سلسلة الأنثطة للعمليات الداخلية

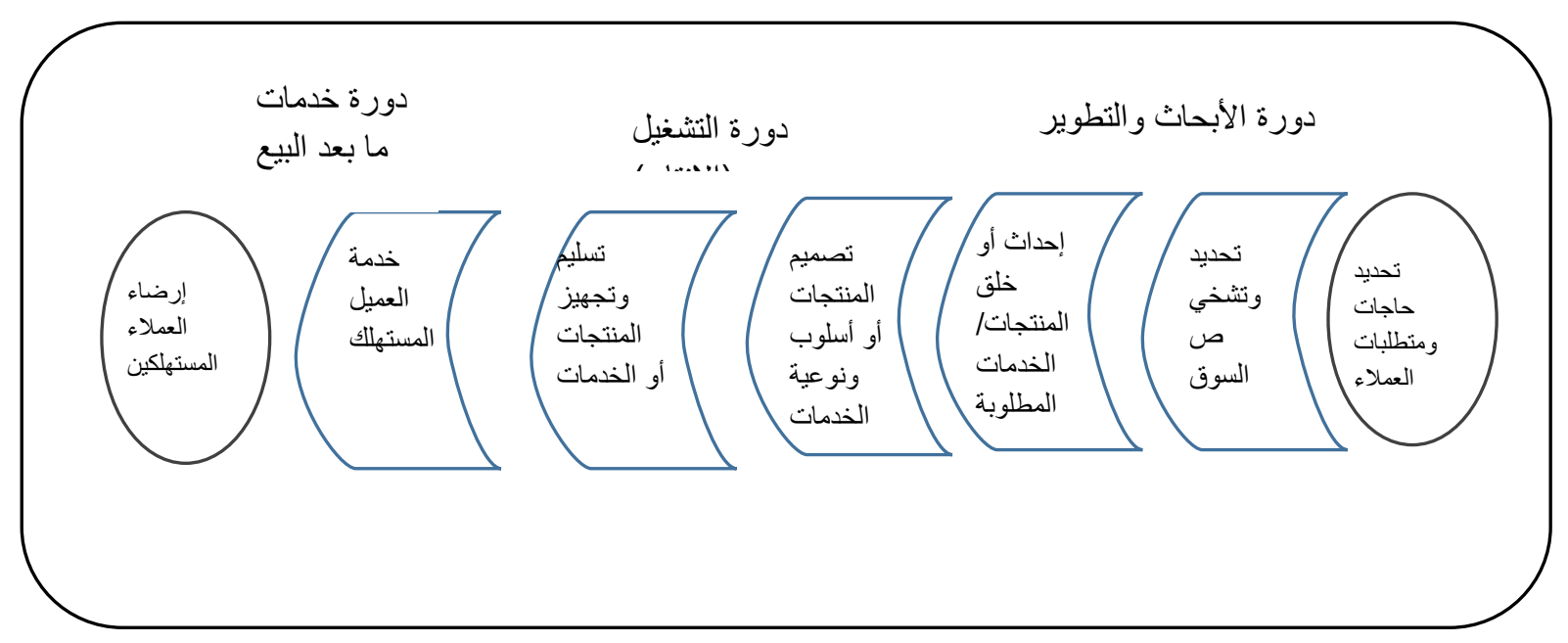

المصدر: (Kaplan and Atkinson (1998:371، )، (أبو جزر، 2012: 55)

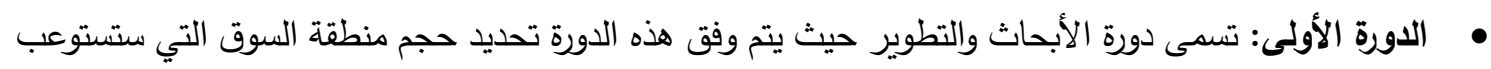

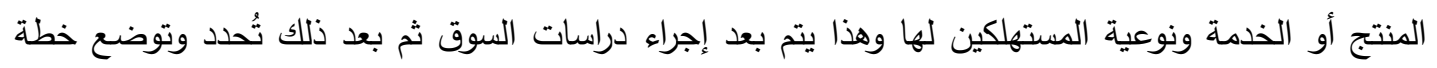

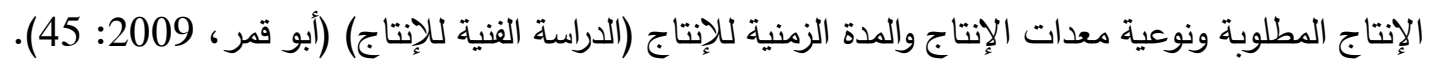


• الدورة الثانية: وتسمى دورة الإنتاج حيث يتم تحديد التصميم المطلوب للمنتج أو الخدمة وأسلوب الإنتاج للمنتجات

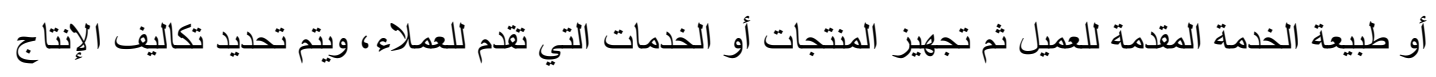

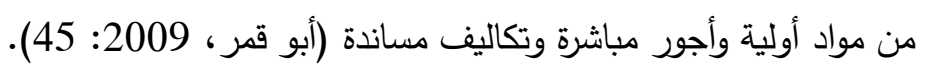

الدورة الثالثة: والتي تسمى دورة خدمة ما بعد البيع وهي المرحلة الأخيرة من دورة حياة المنتج الكلية، وتركز

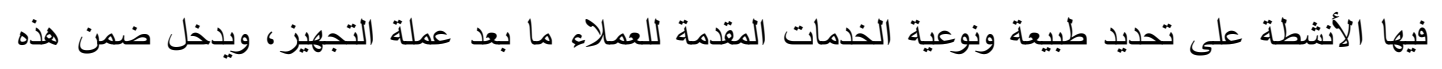
الدورة المدة الزمنية المحددة لتقديم الخدمات وبرامج التعليم والتدريب التي تعدها المنظمة لتدريب العملاء المستهلكين على كيفية استخدام المنتج المقدمة لهم (البشتاوي، 2001: 108).

4- بُعد التعلم والنمو Learning and Growth Perspective (لتحقيق رؤيتنا، كيف سنحتفظ بقدرتنا

على التغيير والتحسين؟).

إن بُعد التعلم والنمو يضمن للمنظمة القدرة على التجديد حيث يعتبر الثرط الأساس للاستمرار والبقاء على التى

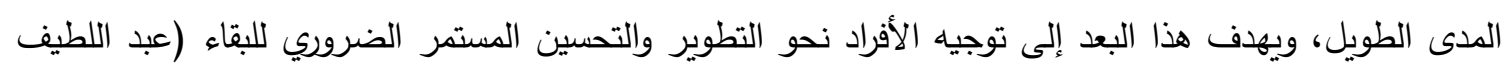

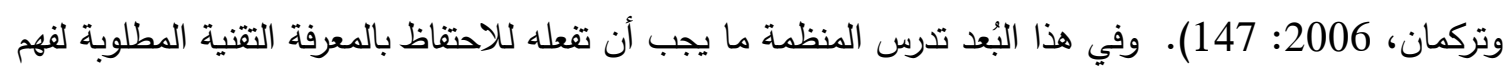
وإشباع حاجات العملاء، وتطور تلك المعرفة إلى جانب اهتمامها بدراسة كيفية الاحتفاظ بالكفاءة والإنتاجية الضرورية

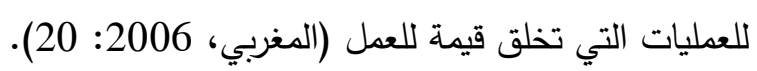
ويُعد هذا البُعد ذو أهداف استراتيجية للمنظمة ونظرتها المستقبلية، إذ يركز على تطوير قدرات العاملين داخل المنظمة كونهم البنية التحتية لها والتي تعمل على بناء المنظمة وتطويرها لأجل طويل، وكذلك طبيعة الأنظمة

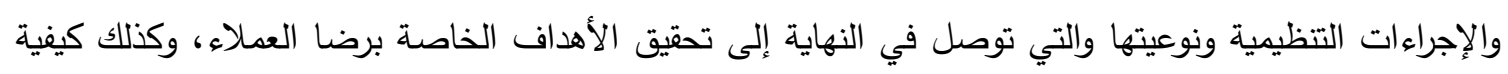

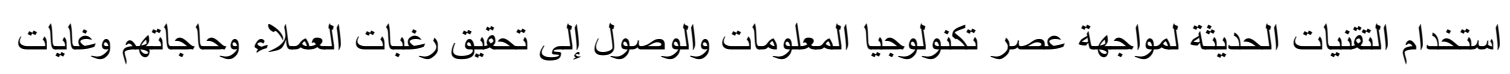
الملاك (البشتاوي، 2004: 403).

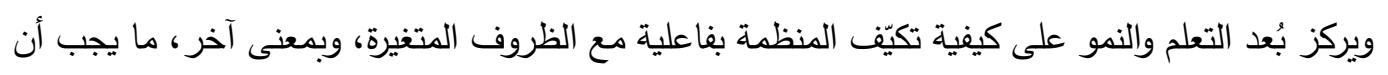

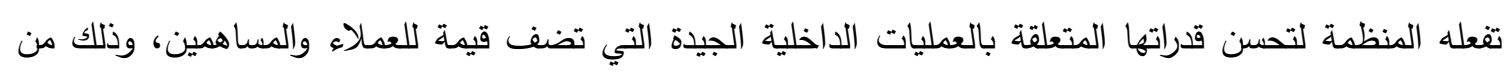

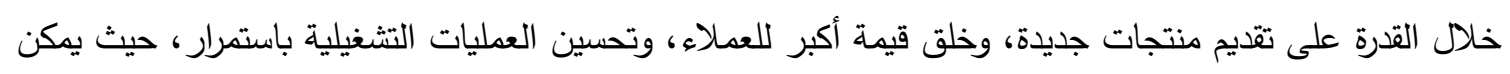

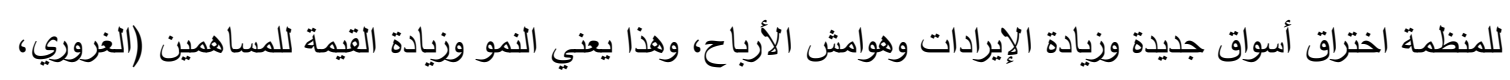

.65:1998

ويجب على المنظمة أن تتعامل مع المنافسة وذلك من خلال تحليل استراتيجيات المنافسين ودراسة مدى

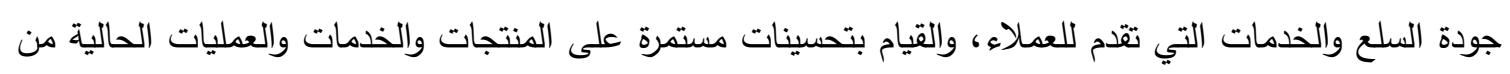
أجل ضمان التميز في تقديم السلع والخدمات للعملاء وضمان ولاءهم وزيادة الحصة السوقية للمنظمة (أبو قمر ،

. 2009

يؤكد كل من (Kaplan and Atkinson،

تتمية قدراتها لتحقيق قيمة للعملاء والمساهمين، ولتحقيق ذلك يجب العمل على تطوير المهارات والقدرات الحالية

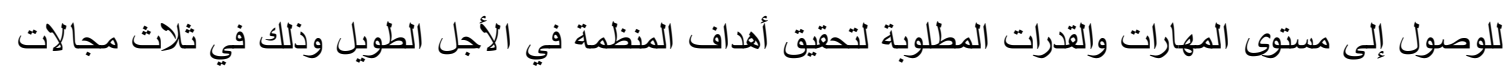

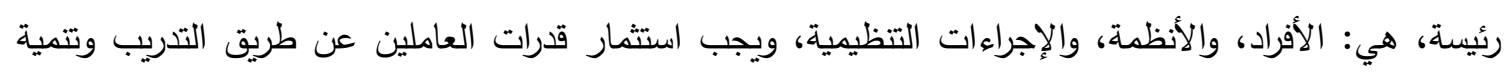
المهارات وتطوير كفاءتهم وإدخال أنظمة المعلومات الحديثة وتطوير الإجراءات التتظيمية، فيجب ولئلى على كل العاملين في المنظمة أن يبحثوا باستمرار عن الابتكار والتحسين لكل جوانب العمل في المنظمة وذلك للحفاظ على المزايا 
التتافسية وتحسينها في المستقبل، كما يجب الدفع بالمنتجات الجديدة نحو الأسواق بسرعة وفاعلية، ويجب البحث عن طرق لتخفيض التكلفة باستمرار وإيجاد طرق جديدة لإضافة قيمة للعملاء ومراعاة هدف التحسين المستمر في حاجاتهم (أبو شرخ، 2012: 20 (40).

5- البعد الاجتماعي Social Perspective (كيف نخدم ونساهم في تطوير المجتمع؟).

بين (السبيعي, 2009) أن هذا البعد يركز على تطوير المجتمع والاهتمام بمتطلباته، حيث ان المساهمة

في دعم المجتمع يعتبر واجباً وطنياً على منظمات الأعمال، ويتم ذلك من خلال دعم الأنشطة الاجتماعية والتتويع في خدماتها المقدمة للمجتمع، والمساهمة في توفير الخدمات الصحية والتعليمية والكثير من المساهمات التي يحتاجها المجتمع (السكن، البنية التحتية والطرق) في ظل الظروف الراهنة الصعبة التي تواجه جميع المجتمعات (عبيد,

وقد ظهر تأكيد على التزام المنظمة اتجاه المجتمع المحيط بها بالعمل على المساهمة في محاربه التلوث، المحافظة على البيئة وخلق فرص عمل متكافئة، والمساهمة في حل مشاكل الإسكان والمواصلات، لذا تحقق المنظمات بلهي

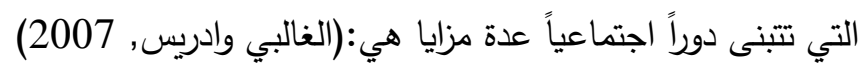

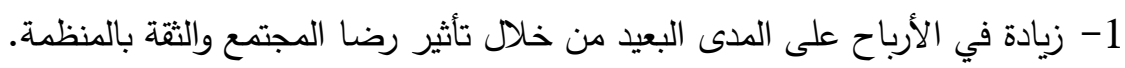

2- تعزيز الميزة التنافسية والثهرة التي تسعى المنظمة الى تحنى تحقيقها.

3- تقليل من الإجراءات الحكومية وتدخلها في شؤون الأعمال.

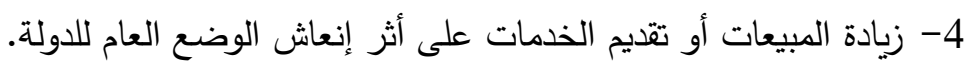
5- تعتبر وسيلة وقائية لتجنب المشكلات الاجتماعية المعقدة.

ويجب ان يتتاسب حجم الدعم المقدم من قبل المنظمات للمجتمع مع ميزانية وحجم وعمر المنظمة (السبيعي,

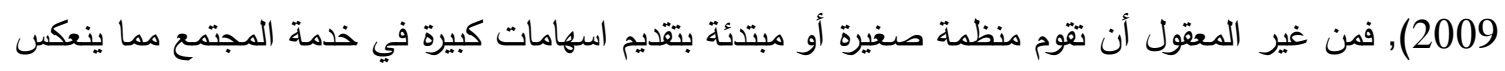

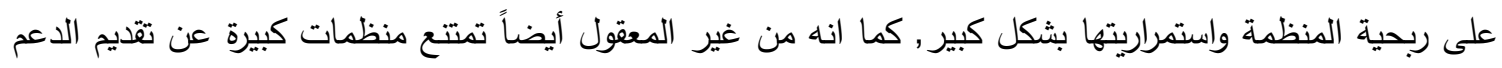
للمجتمع التي ترعرعت فيه, او القيام بتقديم الدعم القليل بما لا يناسب مع حجمها, ولخدمة المجتمع أشكال كثيرة

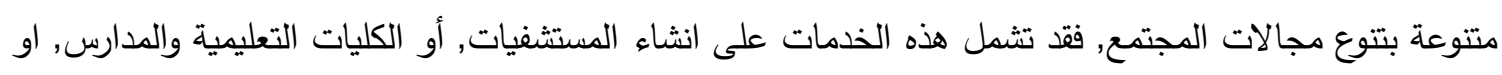

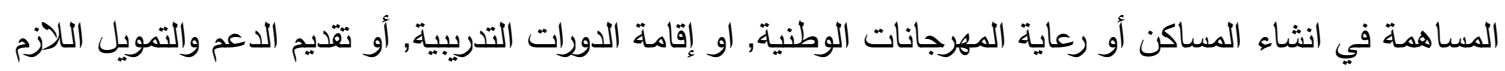

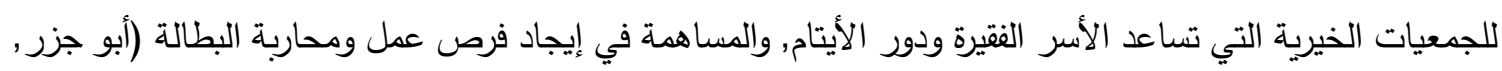

المحاور التي يحتوي عليها كل بُعد من أبعاد بطاقة قياس الأداء المتوازن

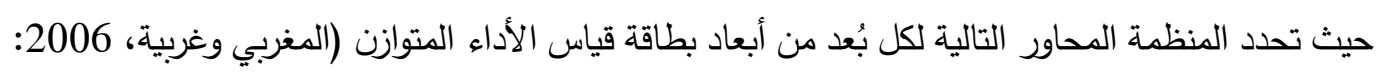

: 82: 213-210 و(غوث، 2005)

\section{1- الأهداف (Objectives)}

تعبر الأهداف عن النتائج المنشود تحقيقها والتي تساهم في تحقيق رؤية ورسالة المنظمة، يتم توزيع وتخصيص

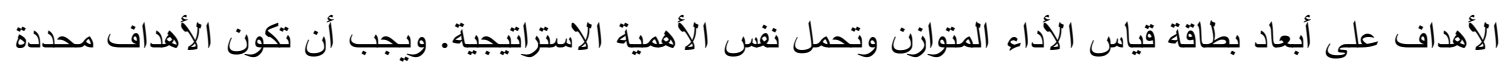

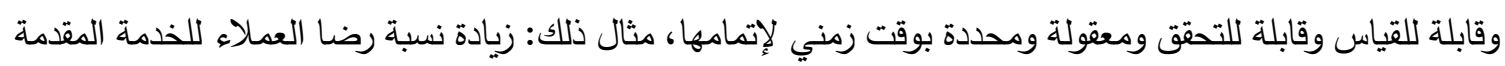
بنسبة 10\% في نهاية العام الحالي. 
2- المقاييس أو المؤشرات (Measures or Indicators)

تمثل المجس الذي يحدد حالة الهدف المراد تحققه عن طريق مقارنته بقيمة محددة سلفاً، فهي تعكس مدى

$$
\text { التقدم نحو تحقيق الهدف الاستراتيجي المحدد، مثال ذلك: مؤشر رضا العملاء (مسح ميداني). }
$$

3- المعايير أو القيم المستهدفة (Target)

مقدار محدد يتم القياس بناء عليه لتحديد مقدار الانحراف (سلباً أو إيجاباً) عن القيم التي تم الوصول

إليها، مثال ذلك: تحقيق رضا العملاء بنسبة 80\% من القيمة المستهدفة.

4- المبادرات أو الخطوات الإجرائية (Initiatives)

تثير المبادرات إلى المشاريع التثغيلية اللازمة تتفيذها لتحقيق الهدف، مثال ذلك: فتح فروع جديدة وتوسيع

مكاتب خدمات العملاء.

الصفات الأساسية لبطاقة قياس الأداء المتوازن

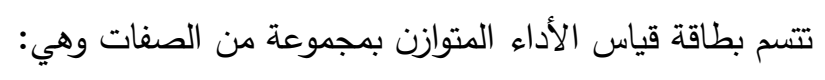

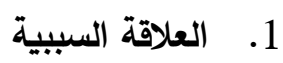

Kaplan and ) ترتبط مقاييس بطاقة الأداء المتوازن في سلسلة من علاقات السببية ولهذا فقد أكد كلاً من الكنابه

(Norton

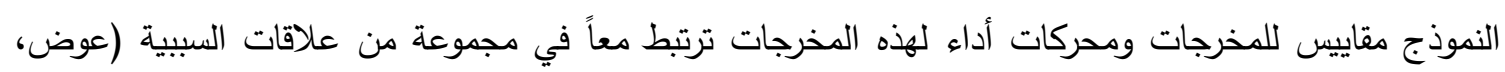
.) 2009

يؤكد (2006،Kaplan and Norton) إن التحسين في التعلم والنمو يؤدي إلى تحسين كفاءة عمليات

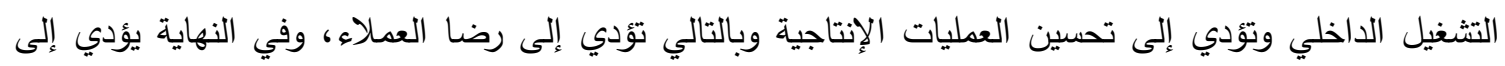

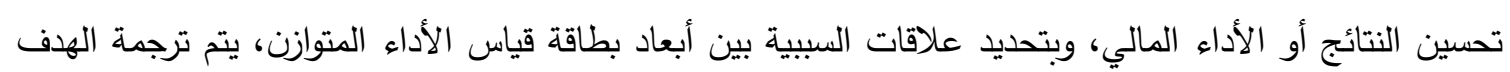

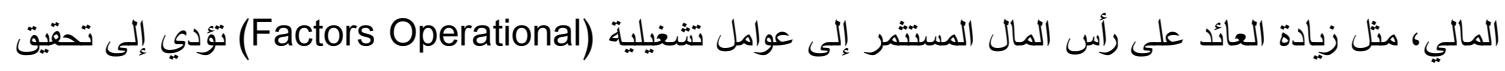
هذا الهدف، وبتقييم العوامل التي تؤثر على الأداء المالي في كل من الجوانب الأربعة لبطاقة قياس الأداء المتوازن،

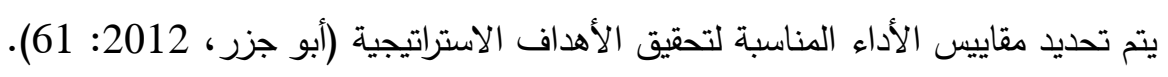

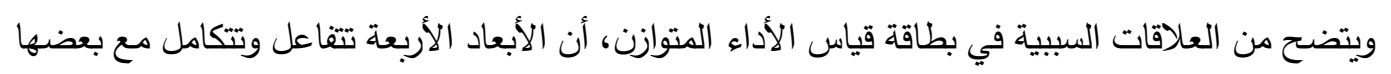

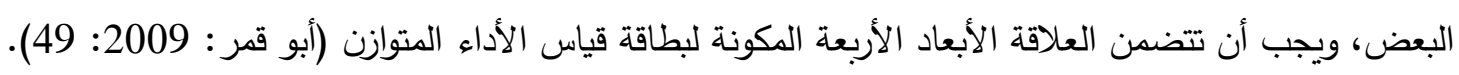

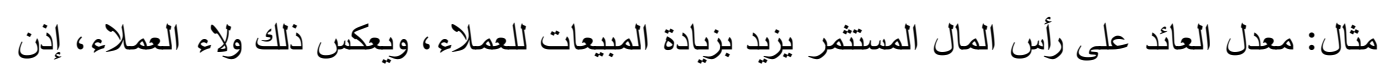

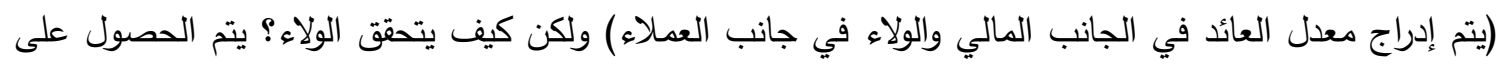
الولاء بتحسين وقت الخدمة للعملاء إذن (ندرج الولاء ووقت الخدمة للعملاء في جانب العملاء من البطاقة) ولتحقيق ولتهن وقت خدمة قصيرة يجب تقليل وقت أداء العمل وإجادة العمليات الداخلية (يتم إدراجهم في العمليات الداخلية) وهذا يتم الحصول عليه بالتدريب وتتمية المهارات للموظفين (يتم إدراجهم في جانب التعلم والنمو) (المغربي وغربية، 2006: 
والثكل رقم (4-3) يوضح علاقة السببية (الأثر والنتيجة) لبطاقة قياس الأداء المتوازن:

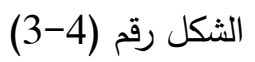

العلاقات المترابطة (السببية) لبطاقة قياس الأداء المتوازن

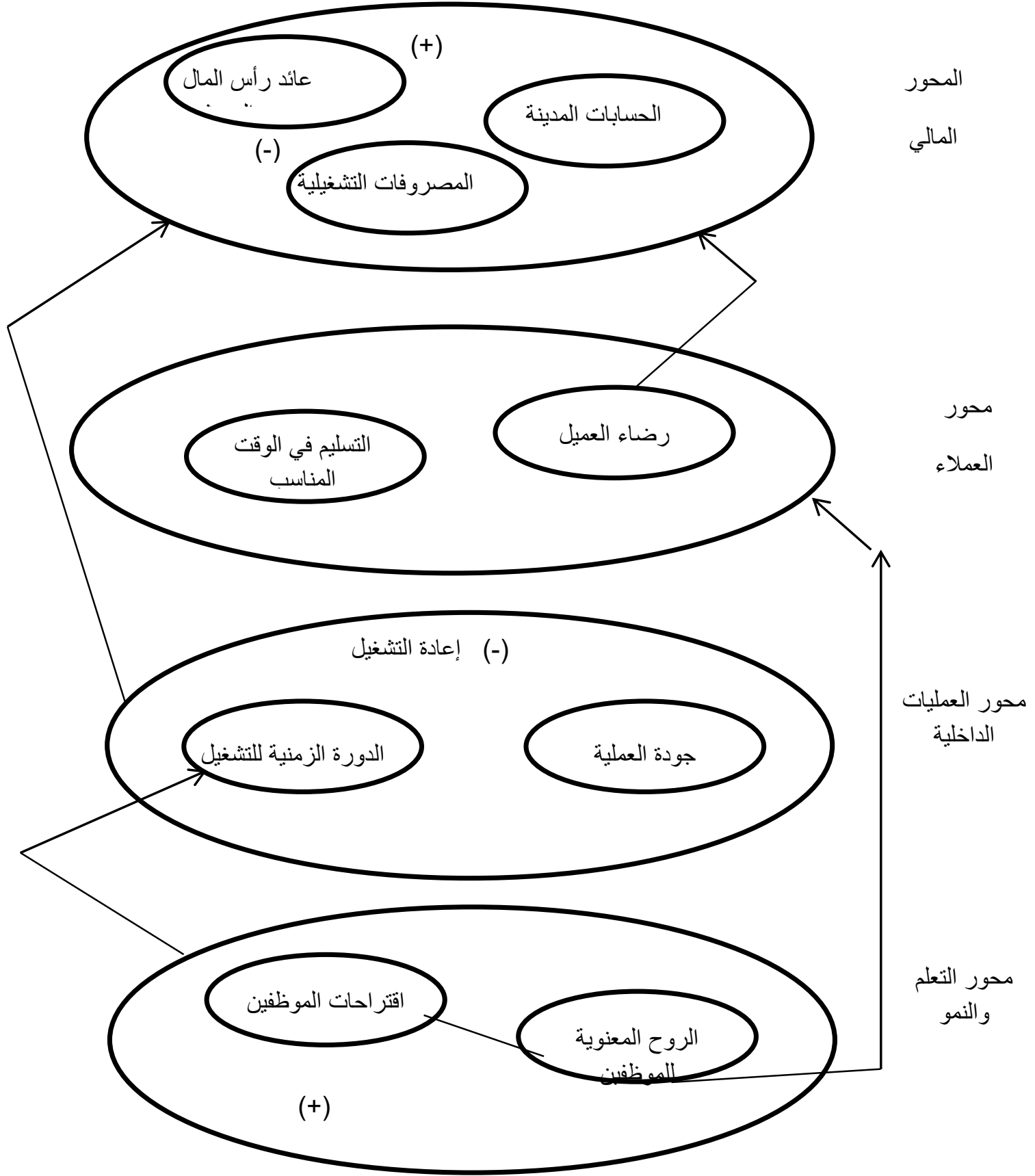

(1996: 255،Kaplan an Norton) المصدر

ويلاحظ من الثكل السابق وجود علاقات ارتباط طردية بين مجالات الأداء الرئيسة يمكن عرضها على

$$
\text { النحو التالي (غوث، 2005: 94): }
$$

- - الروح المعنوية للعاملين ودرجة الاهتمام بالمقترحات المقدمة منهم في مجال القرارات التكتيكية والاستراتيجية. - - الروح المعنوية للعاملين ومستوى رضا وولاء العملاء وثتتهم في تميز المنتج من حيث الجودة والتكلفة.

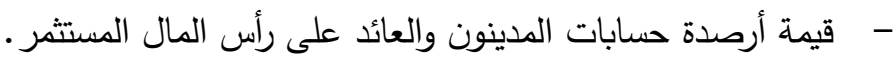




$$
\begin{aligned}
& \text { 2. - أن هناك علاقات بين كل من: - } \\
& \text { - - المقترحات المقدمة من العاملين ومستويات إعادة التشغيل وتعديل العمليات. } \\
& \text { - مستوى رضا وولاء العملاء وقيمة أرصدة حسابات المدينون. }
\end{aligned}
$$

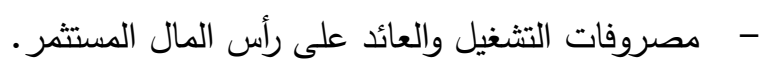

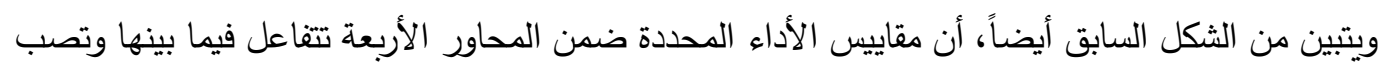
في المحور المالي وهذا يتضح من حركة الأسهم الصاعدة من الأسفل إلى الأعلى حيث يتبين من الثكل أنه كلما

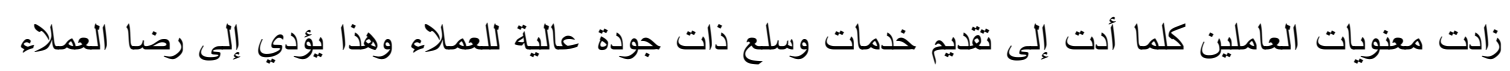
بدرجة عالية تجاه المنظمة ومن ثم هذا الرضا يؤدي إلى تخفيض الحسابات المدينة وبالتالي إلى زيادة العائد على

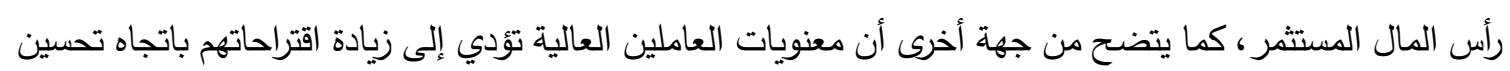
وتطوير الإنتاجية وبالتالي يقلل من المنتجات المعادة والتي تزيد من المصروفات التثغيلية التي تتعكس على تلى تخفيض العائد على رأس المال المستثر .

\section{2. الصفات التعددية (متعدد الأبعاد)}

تسمح صفة تعدد الأبعاد Multi-Dimensions أو تعدد المنظورات Multi-Perspective لبطاقة الابعاد قياس الأداء المتوازن بالنظر إلى منظمات الأعمال من خلال أربعة أبعاد، وتوفر الإجابة على الأسئلة التالية:

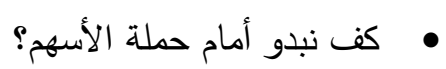

$$
\begin{aligned}
& \text { • • • • • }
\end{aligned}
$$

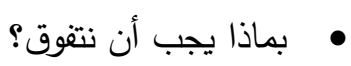

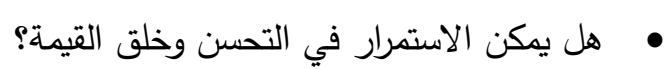

حيث يعبر كل سؤال عن بُعد من الأبعاد الأربعة: البعد المالي، وبعد العملاء، وبعد العمليات الداخلية، وبعد

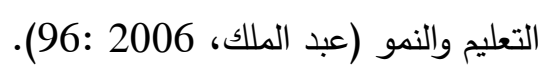

\section{3.}

وهي عبارة عن التقديم المتوازن لكل من المقاييس المالية وغير المالية حيث تقوم بطاقة قياس الأداء المتوازن

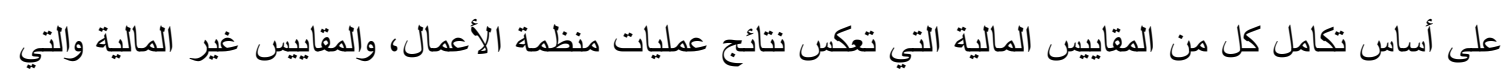
توفر نظرة واضحة عن أسباب هذه النتائج. وكذلك التوازن بين المقاييس قصيرة الأجل التي تقيس النتائج قصيرة الأجل والمقاييس طويلة الأجل التي تقيس النتائج بعيدة الأجل، وأيضاً التوازن بين المقاييس الداخلية والمقاييس لإنيس

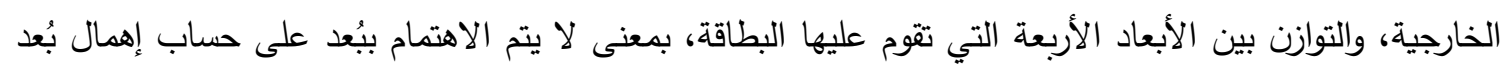

$$
\text { أخر (جودة، 2008: 279). }
$$

\section{4.}

لقد برهن أحد الباحثين على أهمية ربط بطاقة قياس الأداء القائم بخطة الحوافز والمكافآت، وهناك العديد من

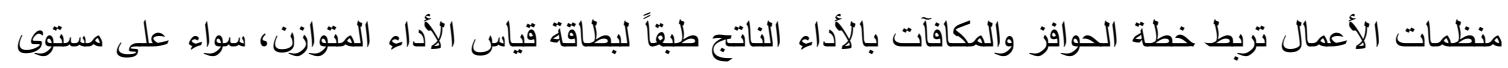

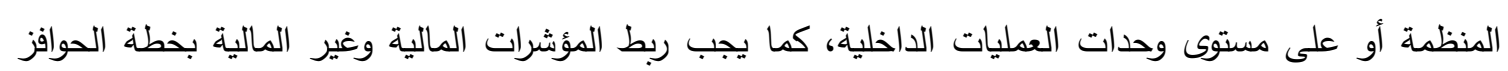

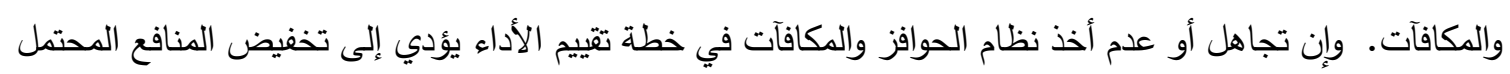
الحصول عليها في حالة الاعتماد على بطاقة قياس الأداء المتوازن بدون أخذ الحوافز والمكافآت بعين الاعتبار (عبد الداء

الملك، 2006: 207). 
إن تطبيق بطاقة قياس الأداء المتوازن بنجاح وبكفاءة بحيث يتم ربط عملية تطبيق البطاقة بنظام فعال للحوافز والمكافآت، حيث إن المكافآت والحوافز تعمل على توافق بين جميع الأفراد وإصرار على تتفذ الخطط كما هو

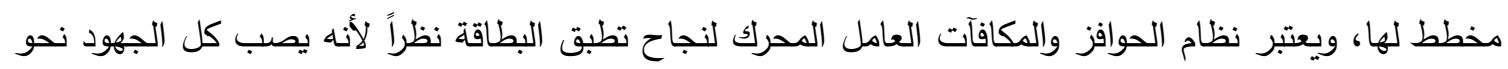
تحقيق أهداف المنظمة (2008: 9،Jakobsen ) . 5. الصفة المحدودية للمعلومات (إتاحة المعلومات بالقدر الذي يلائم طاقة متخذ القرار): نظراً لأن بطاقة قياس الأداء المتوازن تركز على مجموعة محددة من المؤشرات المالية وغير المالية، فإنه يقضي على ظاهرة تحميل متخذ القرار بطاقة تحليلية كبيرة. وفي هذا الصدد حدد BSCI (معهد بطاقة قياس الأداء المتوازن) هذه المقاييس بعدد يبدأ من 15 إلى 20 مقياس، وبمعنى أخر ، من 4 إلى 5 مقاييس لكل بعد من الأبعاد

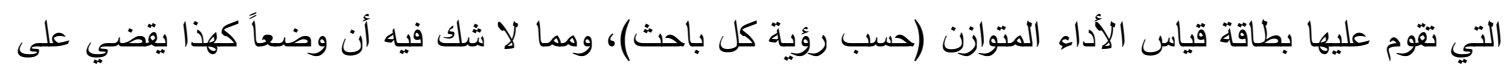

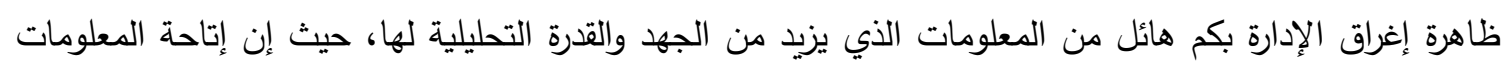

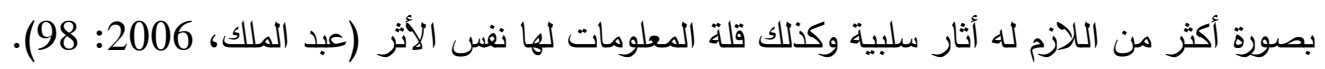

مزايا استخدام بطاقة قياس الأداء المتوازن تعد بطاقة قياس الأداء المتوازن من أهم أنظمة قياس الأداء التي تم تطويرها حديثاً، ويسعى هذا المقاء المياس

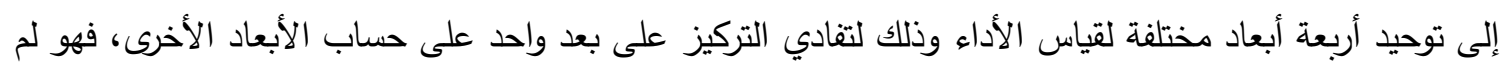

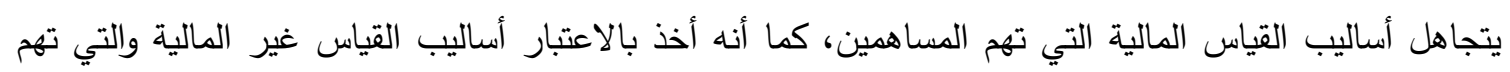
العملاء والعمليات الداخلية والتحسين والنمو والتعلم والابتكار، وإن تطبيق بطاقة قياس الأداء المتوازن يحقق العديد

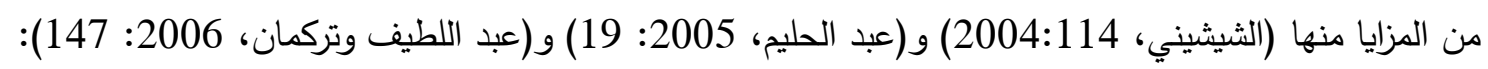
1. تقدم إطاراً شاملاً لترجمة الأهداف الاستراتيجية إلى مجموعة متكاملة من المقاييس التي تتعكس في صورة مقياس أداء الاستراتيجية. 2. تعمل على إشباع عدة احتياجات إدارية لأنها تجمع في تقرير واحد أجزاء عديدة من استراتيجية المنظمة، وتمد الإدارة بصورة شاملة عن عمليات المنظمة. 3. تحمي من حدوث مثالية جزئية لأحد الأبعاد لأنها تجعل المديرين يأخذون في الاعتبار مقاييس أداء الأبعاد الأخرى للبطاقة.

4. تتضمن بطاقة قياس الأداء المتوازن العديد من التوازنات، فمقياس الأداء تتضمن موازنة بين الأهداف طويلة المدى وقصيرة المدى، والتوازن بين المقاييس المالية وغير المالية، وتوازن المقاييس الخارجية والداخلية. 5. تعمل بطاقة قياس الأداء المتوازن على توفير مبادئ توجيهية للتنمية من خلال التركيز على الفوائد المتوقعة. 6. تمكن المنظمة من إدارة متطلبات الأطراف ذات العلاقة (المساهمين، العملاء، الموظفين).

7. تسهل الاتصال وفهم أهداف العمل والاستراتيجيات في مختلف مستويات المنظمة. 8. ت تساعد على الإدارة الفعالة للموارد البشرية من خلال تحفيز الموظفين على أساس الأداء. 9. تزود الإدارة تغذية عكسية استراتيجية وبالتالي تساعد على التعلم.

$$
\text { وأضاف (زغلول، 2010: 13): }
$$

1. يعد مقياس الأداء المتوازن نموذج رباعي الأبعاد فهو ينطلق من أربعة منظورات، هي: منظور الأداء المالي،

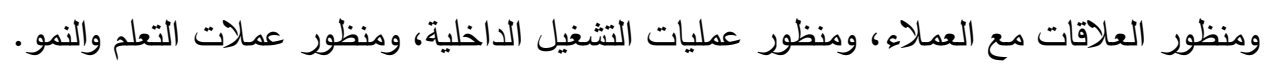


2. تقوم بطاقة الأداء المتوازن على أساس تقسيم كل منظور إلى خمس مكونات، هي: الهدف الاستراتيجي الفرعي، المؤشرات، القيم المستهدفة، الخطوات الإجرائية والمبادرات، القيم الفعلية.

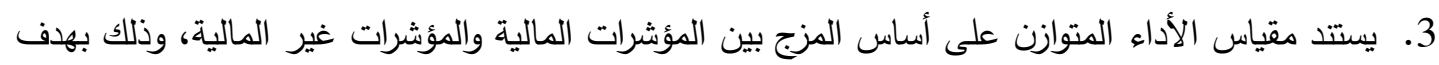

$$
\text { التعرف على مدى التقدم نحو تحقيق الأهداف الاستراتيجية كمياً ومالياً. }
$$

4. إن مقياس الأداء المتوازن يقوم على أساس مجموعة من الروابط الرأسية السببية بين الأهداف الاستراتيجية

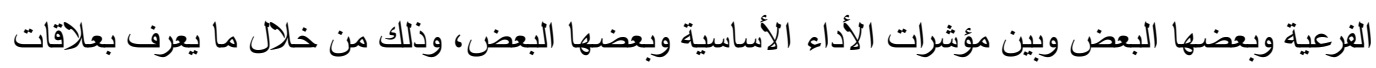

$$
\text { السبب والنتيجة التي تتضمنها الخريطة الاستراتيجية. }
$$

مقومات نجاح تطبيق بطاقة الأداء المتوازن توجد مجموعة متطلبات أسـاسـية لكي يمكن تطبيق مقياس الأداء المتوازن بنجاح يمكن اسـتعراضـهـا فيما

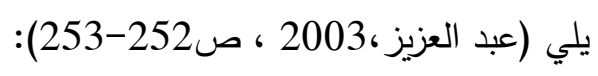

1. تحديد واضح للأهداف الاستراتيجية:

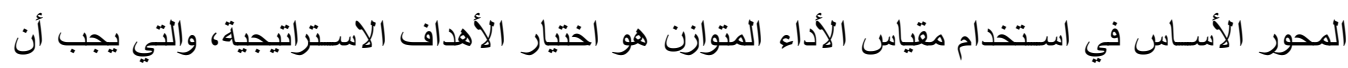

يتوافر فيها مجموعة من المعايير أهمها:

جدوى التنفيذ: ويقصــ به أن تكون الموارد المطلوبة لتحقيق الأهداف، سـواء كانت موارد مالية أو طاقات

إدارية متاحة تأو ممكنة.

القياس: ويقصد به قابلية كل الأهداف للقياس الكمي أو الكيفي من خلال مؤشرات مناسبة.

الأهمية الاستراتيجية: والتي تعني أن يرتبط الهدف الاستراتيجي بميزة تتافسية.

إمكانية التطوير : والتي تعني أن تكون الأهداف الطموحة في حدود المدكن.

درجة التأثير: والتي تعني أن يتوافر في المنشأة الخبرة والقدرة على تحقيق الأهداف.

الطيران بارتفاع مقبول: ويقصد به الأهداف التي تكون خارج نفوذ المستوى الإداري.

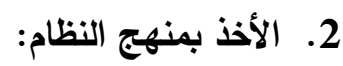

يتوقف نجاح اسـتخدام مقاييس الأداء المتوازن على الأخذ بمدخل النظام، على أن يستخدم هذا المقياس

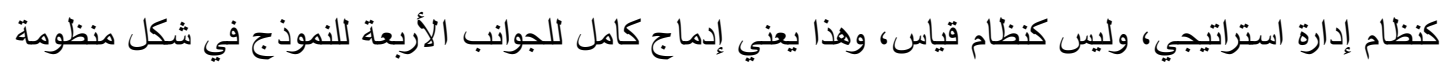

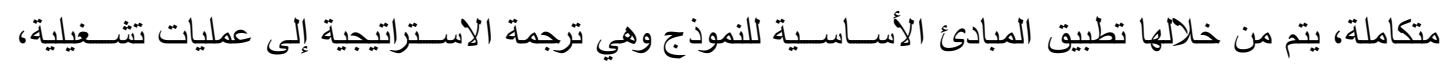

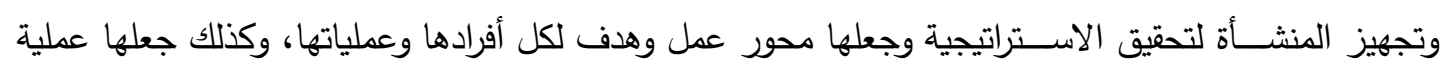
مستمرة، تقود إدارة التغيير من خلال قيادة تتفيذية فعالة. 3. وجود الدافعية لاختيار مقاييس الأداء المتوازن:

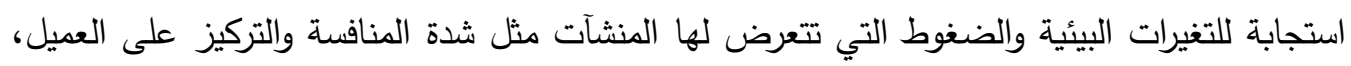
وظاهرة الاندماج الصناعي، وحتمية تطبيق الأنظمة والأساليب المتقدمة في تكنولوجيا المعلومات، فقد كان من

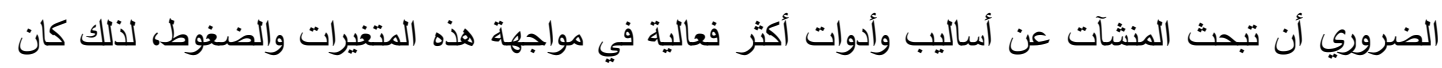
هناك دافع قوي لاى هذه المنثآت لتطبيق مقاييس الأداء المتوازن. ومما سبق يمكن القول أن أي لمؤسسة في سبيل تطبيقها لمقياس الأداء المتوازن، يجب أن أن يكون لديها لادياء

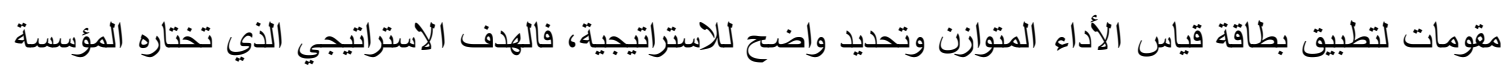
هو أساس تحديد العوامل المؤثرة التي تؤدي إلى نجاحها، وبالتالي فإن المؤسسة التي تستطيع أن تحدد أهدافها 
الاستراتيجية بدقة، هي الأكثر قدرة على تطبيق مبادئ وأسس القياس المتوازن على أن يكون لديها دافعية لتطبيقه بما يمكنها من أن تستخدم المقياس كمؤشر شامل للأداء. التحديات التي تواجه تطبيق بطاقة قياس الأداء المتوازن إن ارتفاع معدل الفشل في تطبيق بطاقة قياس الأداء المتوازن يعتبر موضوع مهم ويثير القلق، ويعتبر مجال واسع للبحث، حيث تواجه منظمات الأعمال تحديات تحول دون تطبيق بطاقة قياس الأداء المتوازن بنجاح، والتحديات التالية هي عبارة عن جزء من التحديات التي تواجه منظمات الأعمال (10) (10): 1. عدم التزام الإدارة والعاملين في عملية تطبيق بطاقة قياس الأداء المتوازن.

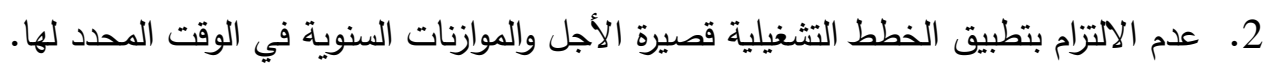
3. القيود المفروضة على نظام المعلومات والتي تحول دون إمكانية تقييم أداء المنظمة، وبالتالي عدم إمكانية مراقبة التقدم نحو تحقيق الأهداف. 4. صعوبات تواجه فريق العمل في رسم الخريطة الاستراتيجية. 5. عدم التوافق في الآراء بشأن اختيار مقاييس الأداء. 6. مقاومة العاملين للتغيير. ومن وجهة نظر الباحث فإنه يمكن التغلب على هذه التحديات من خلال:

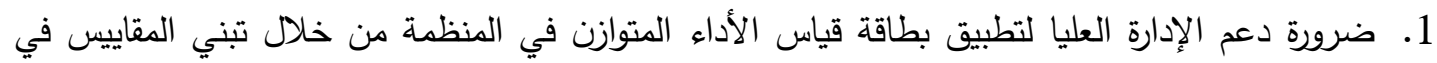

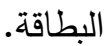

2. تشجيع الموظفين من خلال منح الحوافز المادية والمعنوية لكل موظف يساهم في تطبيق ودهم النظام 3. ضرورة إثرالك جميع العاملين في الآراء ووضع مقاييس ومحركات الأداء حتى يتم التوافق عليها.

\section{خطوات تصميم وتطبيق مقياس الأداء المتوازن}

أُجريت دراسات عديدة بهدف تحقق فعالية وشمولية وتوازن نظام تقييم الأداء المالي والتشغيلي وكان من

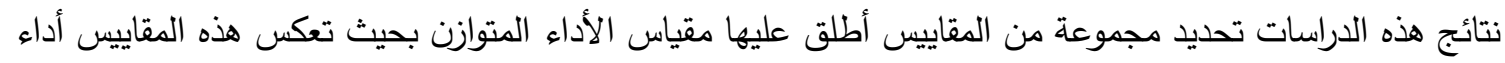
المنثأة من أربع محاور متمثلة في محور العملاء، محور المساهمين، محور العمليات الداخلية، محور الابتكار والتجديد (النمو والتعلم). ولقد تعددت آراء الكتاب والباحثين حول الخطوات اللازمة لتصميم وتطبيق مقياس الأداء

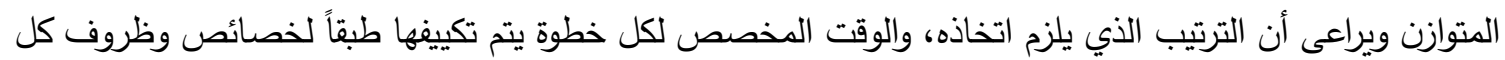

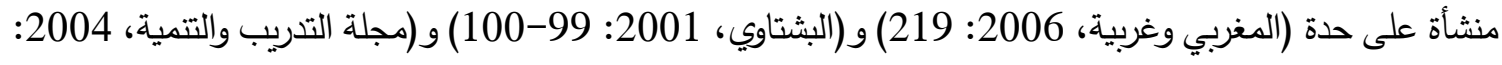
23-24). والثكل رقم (5-3) يوضح الخطوات التفصيلية اللازمة لتنفيذ مقاس الأداء المتوازن (المغربي وغربية، 


$$
\text { شكل رقم (5-3) (3) }
$$

خطوات تنفيذ مقياس الأداء المتوازن

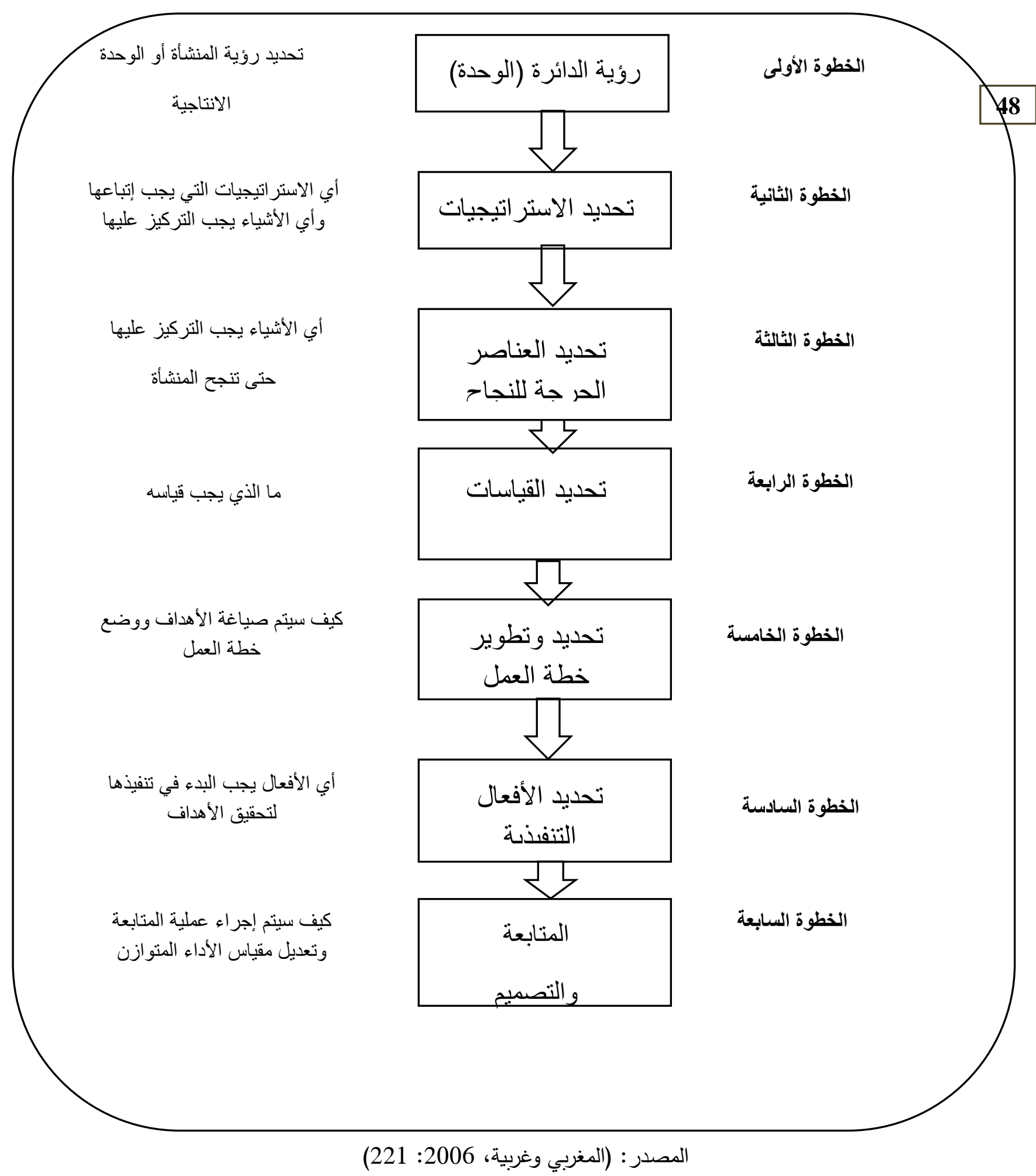


1: صياغة رؤية الدائرة (الوحدة) التنظيمية وقد بين (2007 :98،Christinian and Beiman ) أنه يجب على الدائرة (الوحدة) أن تحدد أولاً رؤية ورسالة وحدة الأعمال الاستراتيجية، وبوجه عام فإن مقياس الأداء المتوازن يقوم على رؤية شاملة مشتركة يلائم وحدة

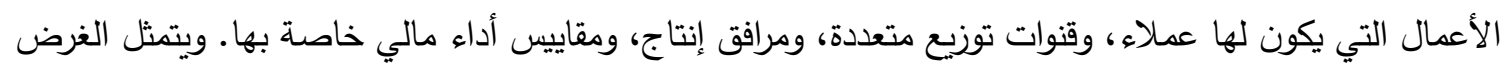

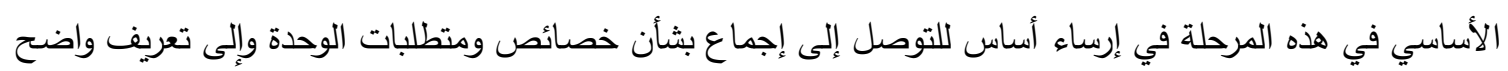
لوضع المنشأة الحالي ودورها، وكذلك الوصول إلى اتفاق حول الكيفية التي ستطور بهاء الخدمة في المستقبل، ويتم التهان

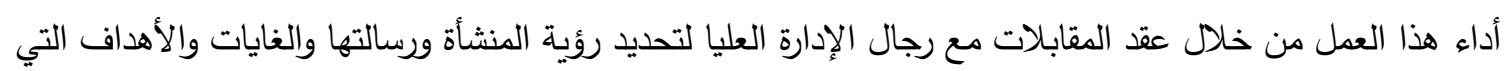

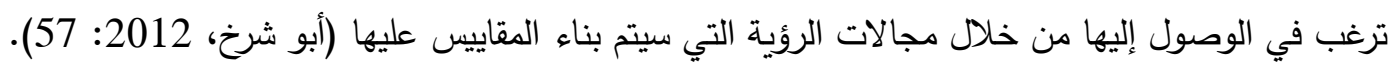

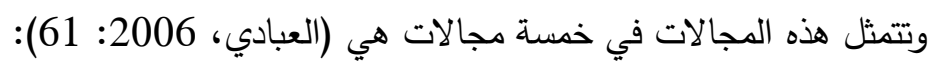
1. العملاء (كيف يرانا العملاء): تهتم مقاييس الأداء الخاصة بوجهة نظر العملاء بتحقيق رضاء العملاء من التهاء خلال مقاييس الجودة، الدقة في التسليم، تخفيض السعر ، وتحسين الخدمات المقدمة لهم. 2. أصحاب رأس المال (المقاييس المالية): تهتم مقاييس الأداء الخاصة بوجهة نظر أصحاب رأس المال بتحقيق الحقيق

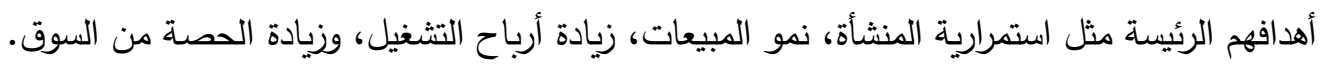

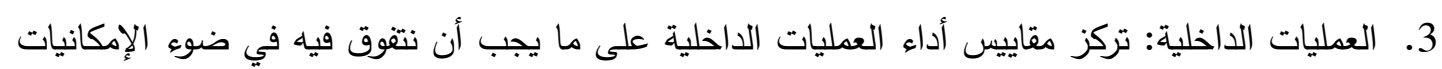
والموارد المتاحة للمنشأة وهي تركز على جوانب ثلاث:

الأول:مقاييس تركز على حسن استغلال الموارد المتاحة لتحقيق رضا العملاء والمحافظة عليهح وزيادة تلادة الحصة من السوق مثل مقاييس الجودة، وتقصي زمن دورة التسليم.

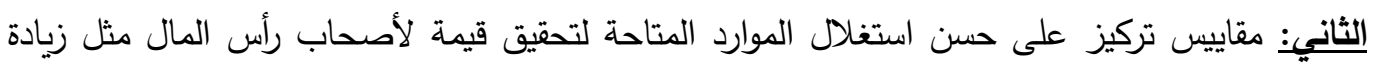
الإتتاجية تتمية مهارات العاملين بما يعمل على تقصر زمن دورة التسليم تخفيض الفاقد في العمليات الإنتاجية تحقيق المرونة في أنظمة الإنتاج.

الثالث: مقاييس تركز على حسن الأداء البيئي لتحقيق أهداف ومتطلبات المجتمع الخارجي مثل معالجة

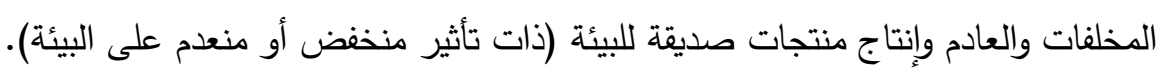

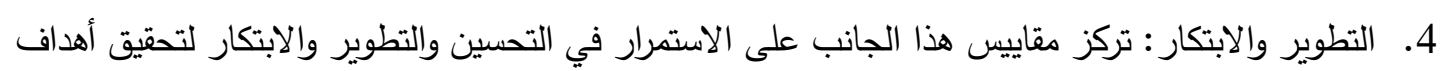
الفئات المختلفة المهتمة بأداء المنشأة مثل: - مقاييس تركز على كسب رضاء العملاء وتتمية الحصة من السوق مثل التطوير المنتجات الحالية تقديم منتجات جديدة مبتكرة. - مقاييس تركز على تحقيق أهداف أصحاب رأس المال وتحقيق كفاءة العمليات الداخلية مثل: تطوير طرق الأداء والتثغيل، وابتكار طرق أداء وتثغيل جديدة بحيث تزيد هذه المقاييس من رضاء العملاء من ناحية

$$
\text { وتزيد القيمة لأصحاب رأس المال من ناحية أخرى. }
$$

- مقاييس تركز على تحقيق أهداف المجتمع من خلال قياس أثر التطوير في المنتجات الحالية وتقديم

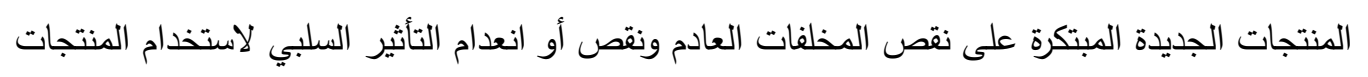

$$
\text { على البيئة. }
$$

2: تحدد الاستراتيجية العامة للمنشأة (رؤية الإدارة العليا)

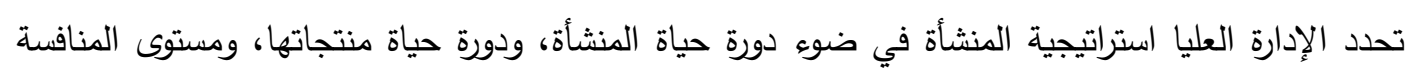

الذي تتعرض له وإمكانياتها ومواردها الداخلية. 
حيث إذا كانت المنشأة جديدة وفي مرحلة النمو وتتعرض لمنافسة شديدة فإنها ستركز على محركات الأداء

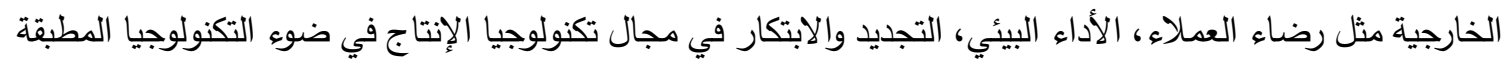

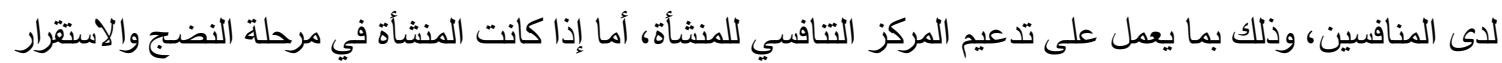
ومنتجاتها تتمتع باستقرار سوقي وموقف تتافسي مناسب، فإن الإدارة العليا تحدد استراتيجيتها على أساس محركات

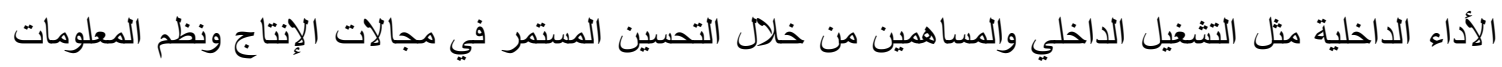
والأساليب الإدارية بما يعمل على تخفيض التكاليف وتحسين الإنتاجية من ناحية وزيادة العائد وزيادة القيمة للمساهمين

$$
\text { من ناحية أخرى (أبو شرخ، 2012: }
$$

3: تحديد عوامل النجاح الحاكمة

يتم في هذه المرحلة تحليل الاستراتيجيات العامة وترجمتها في شكل أهداف استراتيجية لمحركات الأداء الخمسة

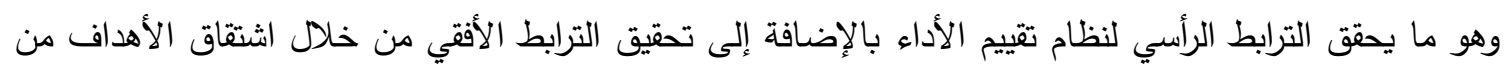
الاستراتيجيات من ناحية وتعاون الأهداف مع بعضها في تحقيق الاستراتيجيات من ناحية أخرى والتي يمكن توضيحها

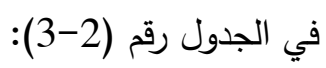

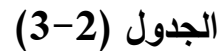

الأهداف الاستراتيجية لمحركات الأداء الخمسة

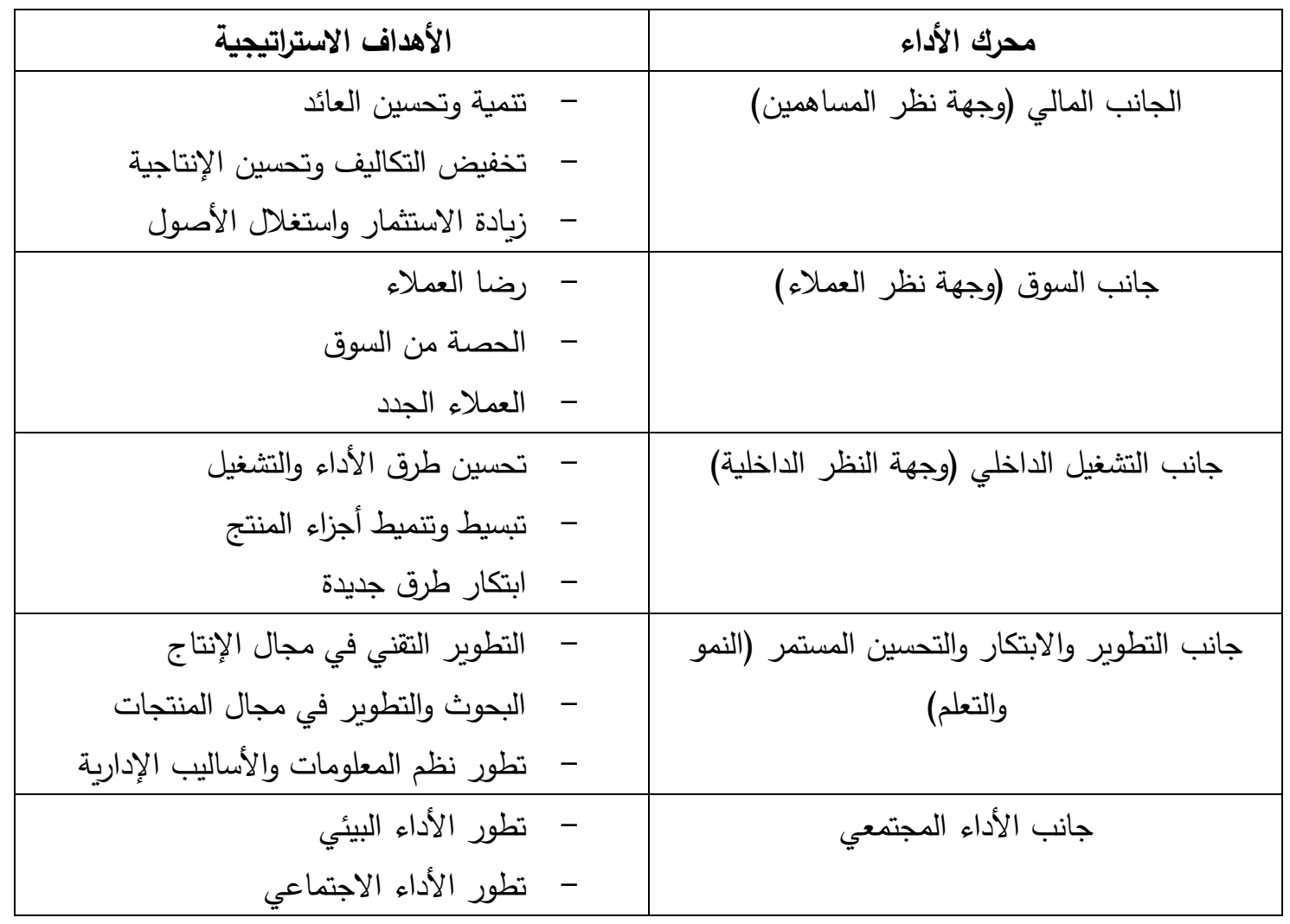

المصدر: (العبادي، 2002: 64) 


\section{4: تحديد مقاييس الأداء للأهداف الاستراتيجية المرتبطة بمحركات الأداء}

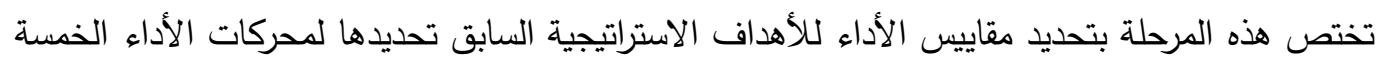

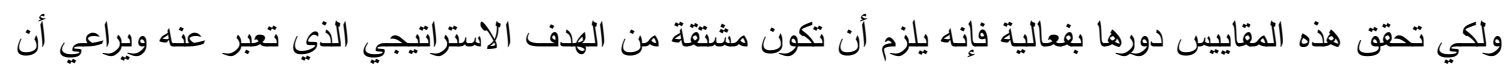

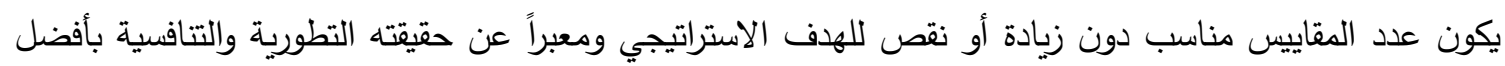
صورة ممكنة ويمكن تحديد مقاييس الأداء المناسبة للأهداف الاستراتيجية السابق تحديدها لمحركات الأداء في المرحلة

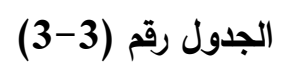

السابقة كما يلي:

مقاييس الأداء المناسبة للأهداف الاستراتيجية لمحركات الأداء

\begin{tabular}{|c|c|c|}
\hline مقاييس الأداء & الأهداف الاستراتيجية & محرك الأداء \\
\hline معدل نمو المبيعات، ربحية كل منتج، ربحية قطاعات العملاء & تنمية وتحسين العائد & \multirow[t]{3}{*}{ 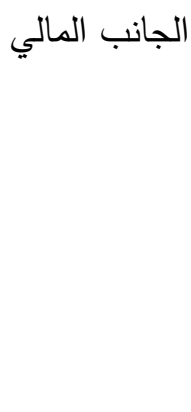 } \\
\hline تمعلفة المنتج إلى تكقيق التكلفة المستهدفة، معدل تحسين المنافسين، معدلات الإنتاجية، نسبة، نسبة & تخفيض التكاليف وتحسين الإنتاجية & \\
\hline العائد على الاستثار في برامج التحسين والتطوير إلى التقفات النقدية. & زيادة الاستثمار واستغلال الموارد & \\
\hline مواعيد التسليم، نسبة المرتجعات، تطور الجودة. & رضاء العملاء & \multirow[t]{3}{*}{ 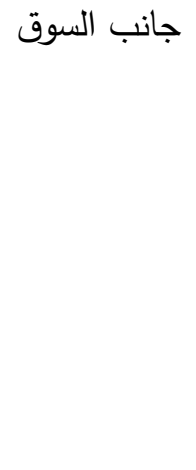 } \\
\hline 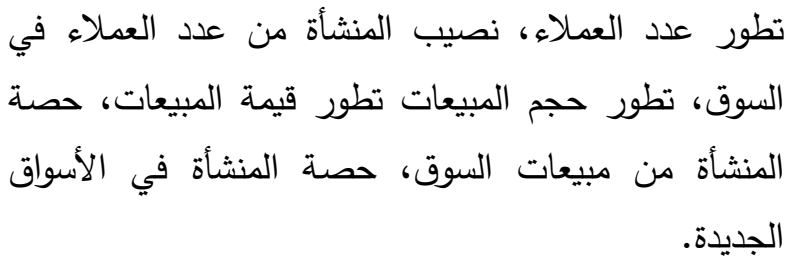 & الحصة من السوق & \\
\hline المنافسة. العملاء الجدد، نسبة العملاء الجدد من المنشآت & العملاء الجدد الجد & \\
\hline 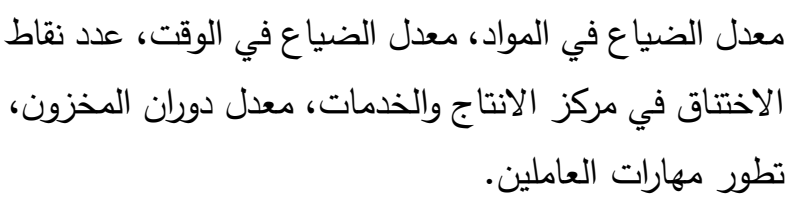 & تحسين طرق الأداء والتشغيل & \multirow[t]{3}{*}{ 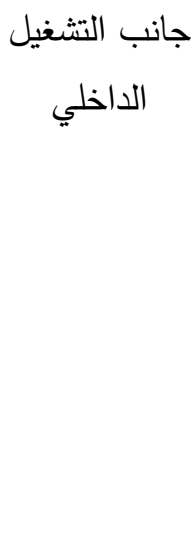 } \\
\hline الاختتاق في مركز الضياع في المواد، معدل الضياع في في الوقتات، عدد نقاط & تبسيط وتتميط أجزاء المنتج & \\
\hline وقت إعداد الخلايا الإنتاجية. & ابتكار طرق تثغيل جديدة & \\
\hline معدل التطور التكنولوجي، معدل الاستجابة التكنولوجية & التطور التقني في مجال الإنتاج & \multirow{2}{*}{ جانب التطوير } \\
\hline 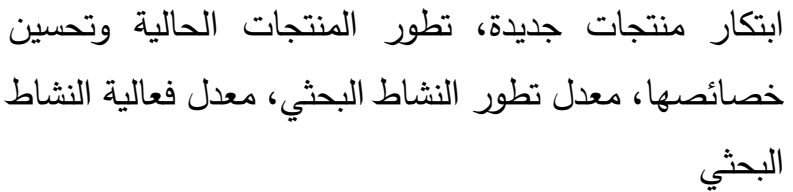 & البحوث والتطوير في الانتاج & \\
\hline
\end{tabular}




\begin{tabular}{|c|c|c|}
\hline الاستجابة لطلبات العملاء، تطور زمن الإنتاج، تطور عدد الموردين، تطور نسبة & الإدارية نظم المعلومات والأساليب & \\
\hline تطعالجة المخلفات، تطور المخالفات، تطور قيمة الغرامات، تطور أساليب & تطور الأداء البيئي & 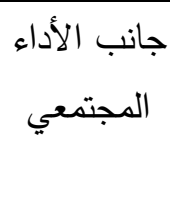 \\
\hline 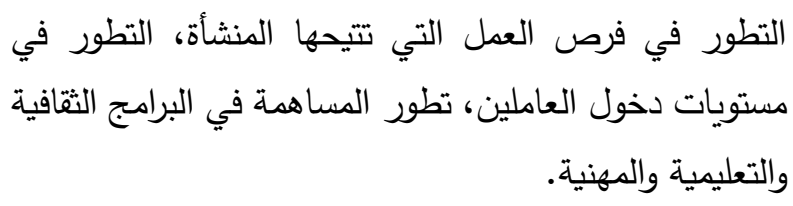 & تطور الأداء الاجتماعي & \\
\hline
\end{tabular}

5: تحديد وتطوير خطة العمل

في هذه الخطوة يتم صياغة الأهداف ووضع خطة العمل ويجب أن تثمل خطة العمل الأفراد المسؤولين

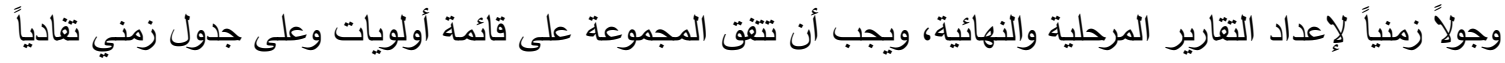
لحدوث مشكلات غير متوقعة (المغربي وغربية، 2006: 2248). وتعتبر مقاييس الأداء همزة الوصل بين الأهداف الاستراتيجية وأداء المستويات التثغيلية والتتفيذية فكما أن الأهداف الاستراتيجية تثتق من الاستراتيجية العامة للمنشأة، فإن مقاييس الأداء في المستويات التتفيذية تثتق من الأهداف الاستراتيجية، ويراعى أن مقاييس الأداء في هذه المستويات تميل للتحديد أكثر من العمومية حتى تكون قابلة

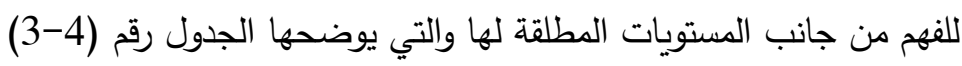

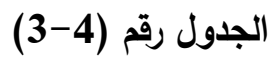

مقاييس الأداء للمستويات التثغيلية والتنفيذية

\begin{tabular}{|c|c|}
\hline مقاييس الأداء & 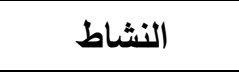 \\
\hline الاستثمارية البرامج البحثية، عدد المنتجات المطورة، عدد المنتجات المبتكرة، تكاليف بحث البرامج & البحوث والتطوير \\
\hline في أجزاء المنتج، عدد الأجزاء النمطية المشتركة في تصنج الوقت اللازم لتطوير وتصميم أحد المنتجات، مقدار التبسيط & تصميم المنتجات \\
\hline 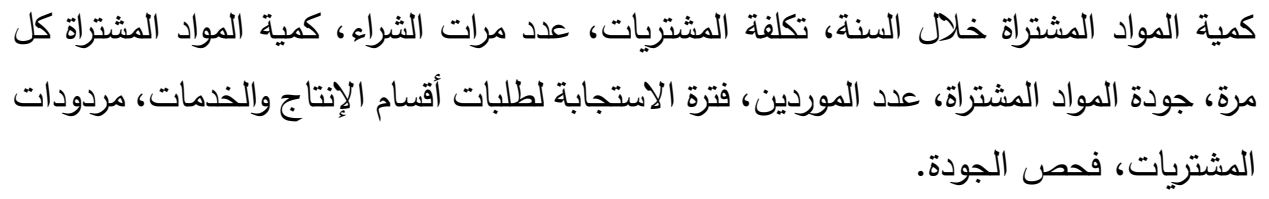 & 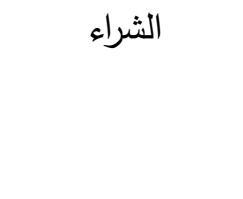 \\
\hline دورة الإنتاج للأمر الإنتاجي الفعلي خلال الفترة، كمية الإنتاج التالف والدعيب، الطاقة الإنتاجية المتاحة، وقت & الإنتاج \\
\hline كمية المخزون خلال الفترة، معدل دوران المخزون/ معدل التالف بالمخازن، فترة تلبية احتياجات & 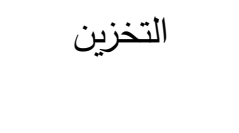 \\
\hline عدد أيام الغياب، ساعات العمل الفعلية، معدل دوران العمل، سيادة روح الفريق. & شئون الأفراد \\
\hline كمية المبيعات مقارنة بالمستهدف، كمية المردودات، وقت التسليم، ربحية العملاء. & البيع \\
\hline
\end{tabular}




\begin{tabular}{|c|c|}
\hline معدل المبيعات الآجلة، نسبة تحصيل الذمم، فترة التحصيل، المسموحات النقدية للتحصيل & التحصيل \\
\hline ساعات الصيانة، ساعات الأعطال الهفاجئة، عدد الأعطال. & الصيانة \\
\hline عدد الإنذارات. الغرامات، عدد المخالفات، عدد القضايا المرفوعة ضد المنشأة بسبب مخالفة قواعد الأداء البيئي، & 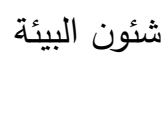 \\
\hline
\end{tabular}

المصدر: (العبادي، 2006: 67)

ويتطلب تبيان الأنثطة والأفعال الواجب البدء في تتفيذها لتحقيق الأهداف والانتقال بالخطة إلى عالم الواقع،

وهذا يتطلب تحديد الأهداف السنوية وتوزيع وتخصيص الموارد، وتحديد المسؤوليات، وتدعيم البرامج، ويقوم فريق التيق

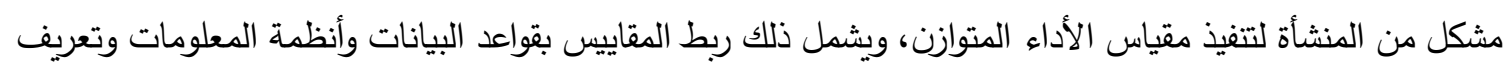
الموظفين العاملين في كافة أقسام المنشأة بمقياس الأداء المتوازن.

7: - المتابعة والتقييم

في هذه المرحلة تقوم المنشأة بمتابعة تحقيق المقاييس من خلال إعداد دليل معلوماتي عن مقاييس الأداء

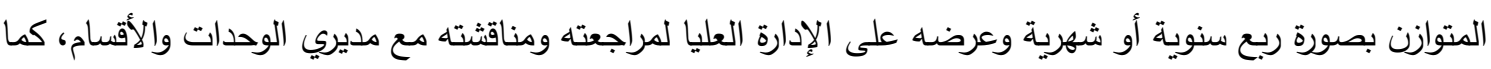

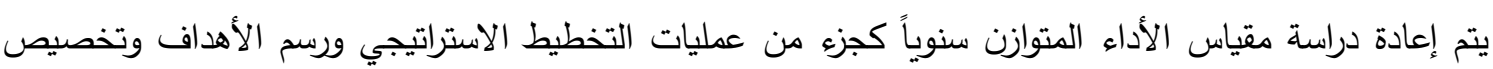
الموارد.

\section{الخلاصة}

من الواضح أن هناك العديد من مقاييس الأداء المالية التي تستخدمها الكثير من منظمات الأعمال في التعبير عن

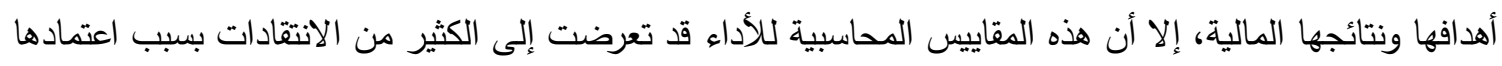
على قيم محاسبية تاريخية. حيث لعدة عقود مضت، كان قياس وتتييم أداء المنظمات يقتصر على الهئ النتائج المالية فقط، ولكن هذا غير كاف للتأكد من سلامة تحقيق المنظمة لرؤيتها ورسالتها مما وجدت العديد من المنظمات الحاجة

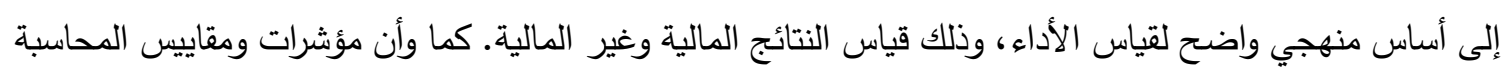
الإدارية التقليدية لم تعد قادرة على إعطاء صورة كاملة عن الأداء المؤسسي الداخلي والخارجي سواء على المدى ولى لإيل القصير أو الطويل ووفق الاحتياجات الاستراتيجية. تتاولت الدراسة تطبيق نموذج بطاقة الأداء المتوازن لتقييم الأداء في الشركات، والبنوك، والجامعات، والوحدات الاقتصادية المختلفة، وبيان أثرها في تعزيز الأداء المالي والاستراتيجي.

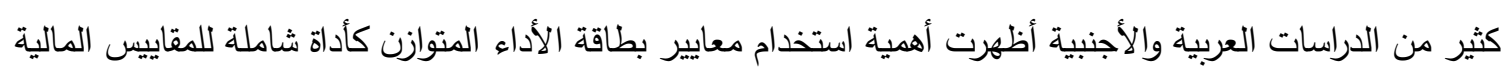
وغير المالية لتقييم الأداء واعتبرته أداه إدارية استراتيجية مههه من أجل تحسين وتطوير مقاييس الأداء المالية والغير

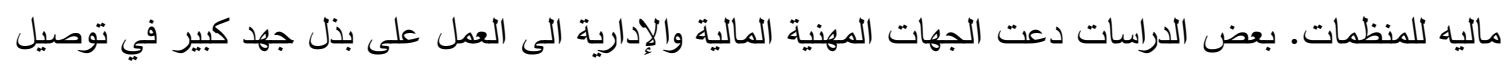
فكرة تطبيق لبطاقة الأداء المتوازن في المؤسسات والثركات الوطنية من خلال عقد ندوات ودورات ومؤتمرات علمية.

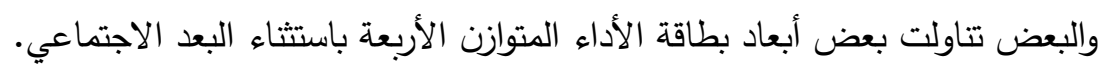


أبو جزر ، محمد أحمد (2012), "استخدام بطاقة الأداء المتوازن كأداة لتقويم أداء البنك الإسلامي الفلسطيني - دراسة ميدانية"، رسالة ماجستير غير منشورة، كلية التجارة، الجامعة الإنسلامية، غزة، فلسطين.

أبو شرخ، جمال حسن (2012), "مدى إمكانية تقويم أداء الجامعة الإسلامية بغزة باستخدام بطاقة قياس الأداء المتوازن - دراسة ميدانية"، رسالة ماجستير غير منشورة، كلية التجارة، الجامعة الإسلامية، غزة، فلسطين.

أبو قمر، محمد أحمد (2009), "تقويم أداء بنك فلسطين الدحدود باستخدام بطاقة قياس الأداء المتوازن"، رسالة ماجستير غير منشورة، كلية التجارة، الجامعة الإسلامية، غزة، فلسطين.

البشتاوي, سليمان حسين (2004), "إطار علمي لجمع المقاييس المحاسبية المالية وغير المالية التثغيلية للأداء في

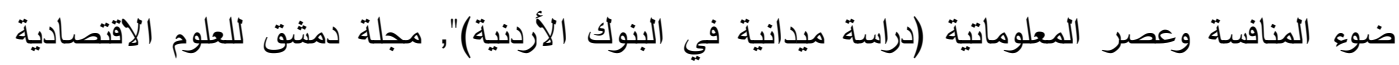

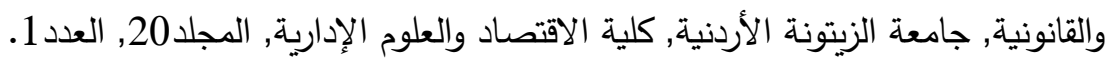

عبد اللطيف, عبد اللطيف وتركمان, حنان (2006), "بطاقة التصويب المتوازنة كأداة لقياس الأداء", مجلة جامعة تشرين للدراسات والبحوث العلمية - سلسلة العلوم الاقتصادية والقانونية, جامعة تشرين, كلية الاقتصاد, دمشق,

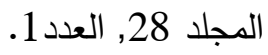

عبيد، وليد (2014) "مدى إمكانية تطبيق بطاقة الأداء المتوازن كأداة لتقويم أداء شركة توزيع كهرباء محافظات غزة "دراسة ميدانية".

عوض، فاطمة (2009) "تأثير الربط والتكامل بين مقياس الأداء المتوازن (BSC) ونظة التطام التكاليف على أساس الأنثطة (ABC) في تطوير أداء المصارف الفلسطينية" (دراسة تطبيقية بنك فلسطين).

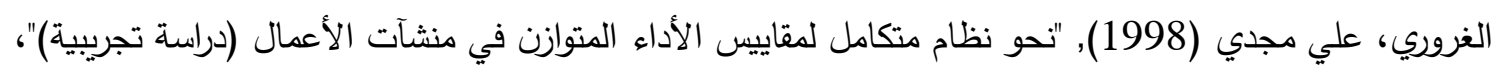

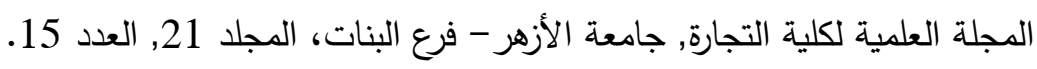

نديم، مريم (2013) "تقييم الأداء المالي باستخدام بطاقة الأداء المتوازن (دراسة اختبارية في شركة طيران الملكية الأردنية)" رسالة ماجستير غير منشورة، جامعة الثرق الأوسط، الأردن.

\section{References}

Abd al-Latif, Abd al-Latif and Turkman, Hanan. (2006). The Balanced Scoring Card as a performance measurement tool. Tishreen University Journal of Scientific Studies and Research - Economic and Legal Sciences Series, 28, (1). (in Arabic)

Abu Jazar, Muhammad Ahmad. (2012). Using the balanced scorecard as a tool to evaluate the performance of the Palestinian Islamic Bank - a field study. [Unpublished master's thesis], Faculty of Commerce, Islamic University, Gaza, Palestine. (in Arabic)

Abu Qamar, Muhammad Ahmad. (2009). Evaluating Bank of Palestine Limited performance using the Balanced Scorecard. [Unpublished master's thesis], Faculty of Commerce, Islamic University, Gaza, Palestine. (in Arabic)

Abu Sharkh, Jamal Hassan. (2012). The extent of the possibility of evaluating the performance of the Islamic University of Gaza using the Balanced Scorecard - a 
field study. [Unpublished master's thesis], Faculty of Commerce, Islamic University, Gaza, Palestine. (in Arabic)

AL Shaikh Ali, Mohammed N. (2007). Performance evaluation of Palestinian telecommunication corporation by using Balanced Scorecard approach. Master research unpublished, college of commerce, Islamic University- Gaza, Palestine.

Alareeni, B. (2018). The impact of firm-specific characteristics on earnings management: evidence from GCC countries. International Journal of Managerial and Financial Accounting, 10(2), 85-104. https://doi.org/10.1504/IJMFA.2018.10012808

Alareeni, B. (2018). Does corporate governance influence earnings management in listed companies in Bahrain Bourse?. Journal of Asia Business Studies, 12(4), 551-570. https://doi.org/10.1108/JABS-06-2017-0082

Alareeni, B., \& Aljuaidi, O. (2014). The modified Jones and Yoon models in detecting earnings management in Palestine Exchange (PEX). International Journal of Innovation and Applied Studies, 9(4), 1472.

Alareeni, B., \& Branson, J. (2013). Predicting Listed Companies' Failure in Jordan Using Altman Models: A Case Study. International Journal of Business and Management, 8(1), 113-126. https://doi.org/10.5539/ijbm.v8n1p113

Alareeni, B., \& Deghish, H. (2016). Applicability of the balanced scorecard to assess performance of Al-Aqsa Media Network Institution in Gaza Strip. IUG Journal of Economics and Business.

Alareeni, B.A. (2019). The associations between audit firm attributes and audit qualityspecific indicators: A meta-analysis. Managerial Auditing Journal, 34(1), 6-43. https://doi.org/10.1108/MAJ-05-2017-1559

Al-Bishtawi, Suleiman Hussein. (2004). A scientific framework for collecting operational financial and non-financial accounting performance measures in light of competition and the information age (field study in Jordanian banks). Damascus Journal of Economic and Legal Sciences, 20(1). (in Arabic)

Al-Gharouri, Ali Magdy. (1998). Towards an integrated system for measures of Balanced Performance in business Enterprises -an empirical study. Scientific Journal of the Faculty of Commerce-Al-Azhar University, 21(15). (in Arabic)

Alqallaf, H. and Alareeni, B. (2018). Evolving of selected integrated reporting capitals among listed bahraini banks. International Journal of Business Ethics and Governance, 1(1), 15-36. https://doi.org/10.51325/ijbeg.v1i1.10

Arshad Ali Javed \& Azhar Iqbal (2008). Swedish mutual funds performance: University of Skovde.

Awad, Fatima. (2009). The effect of linkage and integration between the Balanced Performance Scale (BSC) and the Activity Based Costing System (ABC) on developing the performance of Palestinian banks (Bank of Palestine Applied Study). [Unpublished master's thesis], Faculty of Commerce, Islamic University, Gaza, Palestine. (in Arabic)

Awadh, M., \& Alareeni, B. (2018). Measuring level of voluntary disclosures of banks listed in Bahrain Bourse. J Account Mark, 7(295), 2. https://doi.org/10.4172/2168$\underline{9601.1000295}$

Divandri, A., \& Yousefi, H. (2011). Balanced Scorecard: a tool for measuring competitive advantage of ports with focus on container terminals. International Journal of Trade, Economics and Finance, 2(6), 472. https://doi.org/10.7763/IJTEF.2011.V2.151 
Iselin, E. R., Mia, L., \& Sands, J. (2008). The effects of the balanced scorecard on performance: The impact of the alignment of the strategic goals and performance reporting. Journal of general management, 33(4), 71-85. https://doi.org/10.1177/030630700803300405

Jakobsen, M. (2008). Balanced scorecard development in Lithuanian companies: Case study of the Lithuanian consulting engineering company, MSc in Finance and International Business. [Unpublished Master thesis], Aarhus: Aarhus School of Business, University of Aarhus.

Kaplan, R. S., \& Norton, D. P. (2005). The balanced scorecard: measures that drive $\begin{array}{lll}\text { performance. Harvard business } & 172 .\end{array}$ https://doi.org/10.2307/41165876

Kaplan, R. S., \& Norton, D. P. (2006). Alignment: Using the balanced scorecard to create corporate synergies. Harvard Business Press.

Kaplan, Robert s., and Atkinson Anthony A., (1998). Advanced Management Accounting, (3 ed), new jersey: printice Hall.

Kaplan, S. Robert \& Norton, David P, (1996). The Balanced Scorecard Translating Strategy in Action, Harvard Business Review.

Morisawa, T. (2002). Building performance measurement systems with the balanced scorecard approach. NRI papers, 45, 1-15.

Nadim, Maryam. (2013). Financial performance assessment using the Balanced Scorecard (Study on Royal Jordanian Airlines). [Unpublished master's thesis], Middle East University, Jordan. (in Arabic)

Niven, Paul R., (2006). Balanced Scorecard step by step, John Wiley and Sons, Inc., Hoboken, New Jersey. Published Imultaneously in Canada.

Norman, G. (2010). Likert scales, levels of measurement and the "laws" of statistics. Advances in health sciences education, 15(5), 625-632. https://doi.org/10.1007/s10459-014-9565-x

Obaid, Walid. (2014). The extent to which the Balanced Scorecard can be applied as a tool to evaluate the performance of the Gaza Governorates Electricity Distribution Company, a field study. [Unpuplished work]. (in Arabic) 